\title{
Predictive vehicle ride discomfort model based on in-situ Stevens power law parameters
}

\author{
A N Thite \\ Faculty of Technology, Design and Environment, Oxford Brookes University, Wheatley, \\ Oxford - OX33 1HX, UK. Email: athite@brookes.ac.uk
}

\section{Biographical notes:}

- Anand Thite is an academic in Mechanical Engineering at Oxford Brookes University. He graduated in 1993 with MTech (Indian Institute of Technology, Kharagpur, India) in mechanical engineering and later in 2003 with a $\mathrm{PhD}$ in Sound and Vibration (Institute of Sound and Vibration Research, University of Southampton). Between 1994 and 1999, he worked as an $\mathrm{NVH}$ engineer with a major automotive manufacturer in India where the responsibilities included numerical, experimental and classical design aspects. Anand led a team working on quieter gear train design and manufacturing. Between 2002 and 2007 at ISVR, University of Southampton, he worked as a Research Fellow on a project funded by the Leverhulme Trust to research mid and high frequency vibrations, and as a Ford Research Fellow researching IC engine sound radiation. Anand currently teaches introductory and advanced vibration analysis, $\mathrm{NVH}$ and selected topics in vehicle crash engineering and numerical simulations. His research interests cover a range of topics in both lower and higher frequency vibrations and acoustics. Anand is currently working on projects in statistical structural dynamics, hybrid modelling approaches applied to analysis of vibration and its effects, dynamics of hard and soft tissues and inverse methods applied to dynamics of mechanical systems. 


\begin{abstract}
The current dynamic ride comfort mathematical models don't use Maxwell arrangement of vehicle suspension occurring due to top mount and the discomfort weightings used are based on the shaker table tests which ignore the influence of vehicle dynamics, for example the effect of seat cushion. A refined integrated vehicle-occupant 10 degree of freedom model that includes top mounts is developed to estimate the occupant response to given harmonic input. The dynamic responses are combined with experimentally obtained in-situ discomfort indices for a car that incorporates the effects of features such as seat cushion. The Stevens power law parameters are estimated and compared with previous studies; the perception model is then used to predict discomfort index as a function of frequency. The influence of the relative stiffness of the top mount and suspension damping on the resonance frequencies is discussed. The acceleration in wheel hop mode can be $\sim 3$ times larger than that when top mount is not included. The influence of resonance frequencies suggests importance of not just using frequency average discomfort index while optimizing suspension and seat parameters.
\end{abstract}

Key words: Ride comfort, Four post rig, Stevens power law, Maxwell model, Discomfort index, Top mount, Vehicle suspension 


\section{Introduction}

The vehicle ride comfort and fatigue related to prolonged exposure to vibration are some of the major performance parameters determining competitiveness of vehicles. Vehicle suspension systems aim to control vibration transfer, thereby achieve target level performance; dependent on the pattern of usage, however, vehicle handling and ride comfort performance have contradicting requirements (Gillespie, 1992). In the industry, numerous expensive and time-consuming trials are used to "optimize" the performance. Ideally, a reliable virtual prototype is a solution. The practical usage of a vehicle model is linked and restricted by model complexity and availability of objective-subjective correlation of response. The models based on measured perceived discomfort in a vehicle are not available; currently weightings based on shaker table measurements are used. The object of this research is the development of a predictive, simple but effective vehicle comfort model based on refined representation of vehicle suspension and in-situ measured discomfort curves represented by Steven's power law.

The model to predict discomfort in a vehicle due to vibration can be split into two parts: a) having a good model of a vehicle and occupant to estimate the vibration response and b) using vibrations on seat in estimating the discomfort based on discomfort curves at frequencies of interest. In the approaches currently used for the purpose there is a scope for considerable refinement in both aspects. The vibration perception studies have not been based on in-situ assessments involving vehicle environment, whereas the dynamic models of ride comfort study lack details to represent accurately the steady state frequency domain response nearer the wheel hop frequency.

There have been limited efforts in combining vehicle dynamic response and subjective discomfort ratings to predict the performance. The most common approach currently used in the industry is to derive perceived discomfort in the vehicle as weighted RMS acceleration at the seat level using ISO 2631-1 (1997). However, the predictions based on the standard may not accurately represent in-situ perception (Plewa et al, 2012). The standards, for example, are based on the measurements with rigid seat and no relative motion between footrest and the seat. Furthermore, the frequency weightings provided for all types of rotations is the same. Therefore, the discomfort curves obtained based on the shaker table tests may differ significantly from in-situ (Griffin 1990). Additionally, the relation between vibration stimulus intensity and discomfort is a non-linear function of stimulus amplitude and the non-linearity varies with frequency (Griffin, 2007; Hacaambwa and Giacomin, 2007; Morioka and Griffin, 
2006).

The dynamic models of varying complexity simplified, only including linear dynamic elements, to very complex involving nonlinear elements and fractional differential equations, have been developed to specifically predict vehicle handling and to some extent ride comfort. For ride comfort studies, however, Kelvin-Voigt arrangement is used for connecting spring and shock absorber. Vehicle models of increasing complexities have been integrated with biodynamic models (Bouazara et al, 2006; Bouazara and Richard, 2011; Kubo et al, 2001). A specific application of an off-road vehicle has been explored (Patil et al, 1978). On its own shock absorber has been modelled using complex hydro-mechanical behaviour, for example (Duym, 1997; Sims and Crolla, 2002); these complexities do not allow easy integration of the model in vehicle dynamic application. In passive simplified models, a shock absorber is treated as a viscous damper; the simplest being a linear model. Often, elements connecting the shock absorbers to the chassis are ignored for steady state analysis (for example, (Hegazy and Sandu, 2009)). However, the top mount stiffness (the stiffness in series with the damping element) has been considered for impact harshness studies (Yang and Madepalli, 2005; Lingyang et al, 2010; Yang et al, 2006). The design of top mount was optimised using a quarter car model in a recent study (Kaldas, 2014) by considering all other elements being of constants. Although, the presence of series stiffness due to top mount is beneficial at higher frequencies, it may play a detrimental role at the lower frequencies. The steady state, frequency domain behaviour of vehicle model with top mount and eventual influence on the vehicle comfort are not available.

The discomfort curves obtained from experiments with occupant-car on the four-post rig were published in earlier papers (Ibicek and Thite, 2012, 2014). In that study, the factors that influence human body motion such as relative motion between the seat top and the vehicle floor were included. The discomfort curves so obtained, however, cannot be readily used in predictive models. The mathematical models used for perception studies can be used to overcome this difficulty; the discomfort curves can be represented using Steven's power law parameters (Stevens, 1975). The exponent and constants of the power law provide insight in to the influence of both frequency and magnitude of intensity (Morioka and Griffin, 2006). The representation in this form in turn can be used to predict behaviour at a particular frequency and acceleration amplitude.

In this study, Steven's power law is used to characterise the perceived discomfort and then a predictive model is developed by integrating these with vehicle dynamic response. The in-situ discomfort curves are used for developing an approach to estimate the discomfort 
spectrum for a given input. Here, these curves are mathematically represented; the equations are fitted based on power law to show variation of perceived intensity as a function of physical stimulus. The vehicle dynamic response is calculated using a refined vehicle lumped parameter model that considers flexible mounting of suspension system on to the automobile chassis. To capture coupling between motions of whole vehicle and seated occupant, at least three degrees of freedom (bounce, pitch and roll) of the vehicle body are required. Hence, a 7 DOF model of a vehicle is developed to analyse vehicle bounce, pitch and roll. A 3 DOF occupant seat model is then attached to 7 DOF model to obtain occupant motion in bounce, pitch and roll. A method is proposed which decomposes road input into combination of vehicle heave, pitch and roll inputs. For a combined, complex input a strategy is proposed to retain frequency domain information.

\section{Predictive model of discomfort due to vibration in a vehicle}

The predictive model of vehicle ride comfort essentially has three components: a) mathematical mode of perceived in-situ discomfort rating for given input, b) a model to represent the dynamics of vehicle and occupant and c) road input to the vehicle through tyres. The vibration transmissibility information captures the dynamics of vehicle and occupant. The discomfort in a vehicle may be influenced by the combination of heave, pitch and roll motions. The inputs may also be combinations of heave, pitch and roll. The process can be simplified if the inputs are assumed to be pure heave or pitch or roll; the overall discomfort for a given arbitrary input to the vehicle through wheels may be calculated independently at each frequency. In the following sections, all three aspects of predictive model are introduced and discussed.

\subsection{Mathematical model of perceived discomfort}

Some studies have shown discrepancies between shaker table based predictions and the perceived discomfort in-situ conditions, for example the result of Plewa et al (2012). In fact, very little information is available on the discomfort due to given wheel input in-situ conditions. Recently, in view of the non-availability of discomfort quantification that considers vehicle dynamics, the experimental curves were obtained using in-situ measurements on a car (Ibicek and Thite, 2012, 2014); a mathematical model based on the published discomfort curves will be used in the predictive model. 


\subsubsection{Discomfort curves of in-situ car experiments}

In measuring in-situ discomfort curves for vehicles, the relevant inputs required at the wheels are crucial. The seat-occupant motion is a combination of heave, roll and pitch. The relative contribution can vary depending on the dynamics. The vehicle in-situ measurements were carried out at frequencies between 1 to $15 \mathrm{~Hz}$. The Discomfort Index (DCI) scale used is given in Table 5 (Ibicek and Thite, 2014).

\subsubsection{Stevens power law parameters}

It is well known that the perception and intensity of vibration are related by a logarithmic function. The measured perception is often expressed using Stevens power law (Stevens, 1975) which relates intensity of stimulus to the perceived sensation using a power function. In the current study, power law constant $p$ and exponent $\chi$ relate the stimulus vibration intensity, $a$ and objective perception DCI by

$$
\mathrm{DCI}=p a^{x}
$$

The exponent $\chi$ contains information of growth of sensation. The above parameters of Steven's power law are obtained using DCI in order to develop a predictive model. The power law parameters are estimated for inputs in heave, pitch and roll at frequencies varying from 1 to 15 $\mathrm{Hz}$ using the process given below.

The power law can be rearranged to allow easy estimation of parameters as below.

$$
\ln (\mathrm{DCI})=\ln (p)+\chi \ln (a)
$$

For observed data, from a DCI variation as function of acceleration (a typical DCI curve is shown in Figure 1, for excitations at a frequency), equation (2) can be written in a matrix form as

$$
\mathbf{y}=\mathbf{A x}
$$

where 


$$
\mathbf{y}=\left\{\begin{array}{c}
\ln \left(\mathrm{DCI}_{1}\right) \\
\cdot \\
\cdot \\
\ln \left(\mathrm{DCI}_{n}\right)
\end{array}\right\} ; \quad \mathbf{A}=\left[\begin{array}{cc}
1 & \ln \left(a_{1}\right) \\
\cdot & \cdot \\
\cdot & \cdot \\
1 & \ln \left(a_{n}\right)
\end{array}\right] ; \mathbf{x}=\left\{\begin{array}{c}
\ln (p) \\
\chi
\end{array}\right\} .
$$

Eventually, the power law parameters can be obtained in a least square solution as

$$
\mathbf{x}=\left(\mathbf{A}^{\mathrm{T}} \mathbf{A}\right)^{-1} \mathbf{A}^{\mathrm{T}} \mathbf{y}
$$

The constant and exponent of power law may depend on both the motion type and the input frequency. There have been differing findings so far in the research (Morioka and Griffin, 2006 ) - exponent values that vary in the range 0.46 to 0.99 have been identified and proposed. It is of interest to find how in-situ measured parameters compare with the earlier findings.

\subsection{Refined vehicle-occupant dynamic lumped parameter model}

In this section, the description of a refined integrated dynamic model of vehicleoccupant using lumped parameters is given. Initially a 3 DOF Maxwell suspension model that accounts for occupant dynamics is compared with a Kelvin-Voigt model to analyse its merits. Later, a full vehicle with an occupant is modelled in order to predict the occupant dynamic response.

\subsubsection{Three DOF Maxwell quarter car-occupant model}

The simplest vehicle-occupant model that considers shock absorber mounting stiffness is of three Degree-Of-Freedom (DOF); all three DOFs represent vertical motion. In the model, tyre is represented by stiffness, wheel and associated elements are represented as a mass, and suspension is represented by a spring and a damper with mounting compliance, vehicle body by mass. The seat-occupant combination is modelled by parallel spring and damping element, and a mass. Figure 2 shows schematic of Kelvin-Voigt and Maxwell models representing the corner of a vehicle. The governing equations of motion for the Maxwell model for harmonic input are given by

$$
\left(-\mathbf{M} \omega^{2}+j \omega \mathbf{C}+\mathbf{K}\right) \mathbf{X}=\mathbf{F}
$$

where, mass matrix is 


$$
\mathbf{M}=\left[\begin{array}{ccc}
m_{\mathrm{u}} & 0 & 0 \\
0 & m_{\mathrm{v}} & 0 \\
0 & 0 & m_{\mathrm{o}}
\end{array}\right]
$$

effective damping coefficient matrix is

$$
\mathbf{C}=\left[\begin{array}{ccc}
c-c^{3} \omega^{2} /\left(c^{2} \omega^{2}+k_{\mathrm{d}}^{2}\right) & -c k_{\mathrm{d}}^{2} /\left(c^{2} \omega^{2}+k_{\mathrm{d}}{ }^{2}\right) & 0 \\
-c k_{\mathrm{d}}{ }^{2} /\left(c^{2} \omega^{2}+k_{\mathrm{d}}{ }^{2}\right) & c_{\mathrm{s}}+c k_{\mathrm{d}}{ }^{2} /\left(c^{2} \omega^{2}+k_{\mathrm{d}}{ }^{2}\right) & -c_{\mathrm{s}} \\
0 & -c_{\mathrm{s}} & c_{\mathrm{s}}
\end{array}\right]
$$

effective stiffness matrix is

$$
\mathbf{K}=\left[\begin{array}{ccc}
k_{1}+k_{\mathrm{t}}+c^{2} \omega^{2} k_{\mathrm{d}} /\left(c^{2} \omega^{2}+k_{\mathrm{d}}{ }^{2}\right) & -k_{1}-c^{2} \omega^{2} k_{\mathrm{d}} /\left(c^{2} \omega^{2}+k_{\mathrm{d}}{ }^{2}\right) & 0 \\
-k_{1}-c^{2} \omega^{2} k_{\mathrm{d}} /\left(c^{2} \omega^{2}+k_{\mathrm{d}}{ }^{2}\right) & k_{1}+k_{\mathrm{d}}+k_{\mathrm{s}}-k_{\mathrm{d}}{ }^{3} /\left(c^{2} \omega^{2}+k_{\mathrm{d}}{ }^{2}\right) & -k_{\mathrm{s}} \\
0 & -k_{\mathrm{s}} & k_{\mathrm{s}}
\end{array}\right] .
$$

The elements of matrices are: $m_{\mathrm{u}}$ is the effective mass of the wheel hub, $m_{\mathrm{v}}$ is the vehicle body mass, $m_{\mathrm{o}}$ is the effective mass of seat-occupant combination, $c$ is the suspension damping coefficient, $c_{\mathrm{s}}$ is the seat damping, $k_{1}$ is the suspension stiffness, $k_{\mathrm{t}}$ is the tyre stiffness and $k_{\mathrm{d}}$ is the stiffness connected in series with the damping element. The stiffness matrix, $\mathbf{K}$ has nonlinear elements; it is now dependent on the suspension damping coefficient and frequency. Based on the series stiffness and the damping suspension damping coefficient, the natural frequencies vary. In an automotive vehicle suspension system, to improve NVH performance, the series spring stiffness is likely to be of the order of tyre (Reimpell et al, 2001) for a range of displacements i.e. the effect on second resonance (the wheel hub or hop frequency) is expected to be significant.

\subsubsection{Integrated occupant-vehicle model}

The integrated occupant-vehicle model considered in this study has 10 degrees of freedom (Figure 3); three DOFs of the seat-occupant sub-model (roll, pitch and bounce motion) and 7 DOFs of the full vehicle model. Now each corner of the vehicle model consists of Maxwell sub-model. When arranged in the matrix form, for forced vibration analysis with harmonic input, equations of motion are given by

$$
\left(-\mathbf{M} \omega^{2}+j \omega \mathbf{C}+\mathbf{K}\right) \mathbf{X}=\mathbf{F}
$$

where, $\mathbf{M}$ is the inertia matrix, $\mathbf{C}$ is the damping coefficient matrix, $\mathbf{K}$ is the stiffness matrix, 
$\mathbf{X}$ is the response vector and $\mathbf{F}$ is the force vector. The inertia, damping and stiffness matrices can be constructed using equations given in APPENDIX. The response matrix is given by

$$
\mathbf{X}=\left[\begin{array}{llllllllll}
z & \alpha & \beta & x & \theta & \phi & x_{5} & x_{6} & x_{7} & x_{8}
\end{array}\right]^{T}
$$

and the forcing vector is given by

$$
\mathbf{F}=\left[\begin{array}{llllllllll}
0 & 0 & 0 & 0 & 0 & 0 & k_{\mathrm{t} 1} x_{1} & k_{\mathrm{t} 2} x_{2} & k_{\mathrm{t} 3} x_{3} & k_{\mathrm{t} 4} x_{4}
\end{array}\right]^{T}
$$

where $z$, is the vertical or bounce motion of the seat-occupant combination, $\alpha$ is the pitch motion of the seat-occupant combination, $\beta$ is the roll motion of the seat-occupant combination, $x$ is the vertical or heave motion of the vehicle centre of gravity, $\theta$ is the pitch motion of the vehicle about the centre of gravity, $\phi$ is the roll motion of the vehicle about centre of gravity, $x_{5}, x_{6}, x_{7}$ and $x_{4}$ are the vertical motion of the wheel hubs and $x_{1}, x_{2}, x_{3}$ and $x_{8}$ are the inputs to wheels. The $k$ 's are spring elements which are shown on Figure 3.

The inputs on the wheels are dependent on road profiles. The road profiles are such that the velocity input amplitudes are constant with respect to frequency (Milliken and Milliken, 1995); this has a huge impact on the acceleration response. For example, if $T$ were the transmissibility vibration from wheel to the occupant in vertical direction for the heave input, the acceleration of occupant is given by:

$$
|\ddot{z}|=\omega v T
$$

where $v$ is the velocity input amplitude that is constant. Typically, acceleration response amplitude at the wheel hop frequency is amplified by about 7 times (as natural frequency ratio of wheel hub and vehicle bounce mode is $\sim 7$ ) compared with that at vehicle body bounce frequency. Hence non-consideration of top mount stiffness would have a huge impact on the accelerations experienced by the occupants of a vehicle; weighted acceleration calculated would be much smaller than if top mount were considered.

The parameters used for the model are based on the experimental results which show natural frequencies as listed in Table 3. The typical parameters are shown in Table 4; many of the parameters are estimated using the technique presented in Ref (Thite et al, 2011). The vehicle stiffness' are based on Reimpell et al (2001) and the seat-occupant parameters are such that resonances obtained are representative of measurements performed on the four post rig. 


\subsection{Decomposition of operational road inputs}

As the in-situ discomfort curves used in this study are based independent linear or angular inputs, the road inputs must be decomposed in that form. Here a road input is decomposed into pure bounce, pitch and roll at the contact point of tyre and ground. Let the decomposed inputs be written as $\mathbf{y}=\left[\begin{array}{lll}w & \psi & \gamma\end{array}\right]^{\mathrm{T}}$, where $w$ is the heave or bounce input, $\psi$ is the pitch angular input and $\gamma$ is the roll angular input. Then the decomposition can be written as

$$
\begin{aligned}
& \mathbf{x}=\mathbf{A y} ; \\
& \mathbf{x}=\left[\begin{array}{llll}
x_{1} & x_{2} & x_{3} & x_{4}
\end{array}\right]^{\mathrm{T}} ; \\
& \mathbf{A}=\left[\begin{array}{ccc}
1 & -b / 2 & a / 2 \\
1 & b / 2 & a / 2 \\
1 & b / 2 & -a / 2 \\
1 & -b / 2 & -a / 2
\end{array}\right]
\end{aligned}
$$

where $a$ is the track width and $b$ is the wheel base of the vehicle. Therefore, using MoorePenrose pseudo inverse, we can find the idealised inputs as

$$
\begin{aligned}
& \mathbf{y}=\mathbf{A}^{+} \mathbf{x} ; \\
& \mathbf{A}^{+}=\left(\mathbf{A}^{\mathrm{T}} \mathbf{A}\right)^{-1} \mathbf{A}^{\mathrm{T}} .
\end{aligned}
$$

The decomposed inputs then can be used to predict the perceived discomfort rating.

For defining the inputs and analysing resulting responses two planes are defined based on Figure 3: a) $X-Y$ plane is called the pitch plane and b) $Y-Z$ plane is called the roll plane. The input is called the heave or bounce input when all the tyre inputs are in phase. Two angular inputs are considered; the input is called pitch input when the inputs lying in the pitch plane are out of phase and it is called roll input when the inputs lying in the roll plane are out of phase.

\section{Results and Discussion}

\subsection{Discomfort curve parameters}

The Stevens' power law parameters for all three forms of inputs were estimated using equation (1), characterising discomfort curves. Figure 4 shows variation of exponent, $\chi$ with 
respect to input frequencies. For the heave input the values vary from 0.39 to 0.61 with a mean value of 0.51 and standard deviation of 0.05 . Although, the exponent is not constant over the input frequencies, the variation is small. The mean value is comparable that found by Miwa (1968) as 0.46, but smaller than that found by Jones and Saunders (1974) as 0.93. In a recent study, the exponent was shown to be slightly frequency dependent below $16 \mathrm{~Hz}$ and having an average value of 0.73 (Morioka and Griffin, 2006). This latest study considered perception threshold in the formulation. The power law parameters appear to depend on arrangement of the test set up. The exponent of 0.51 found in this study for in-situ measurements can therefore be reliably used in the predictions of ride discomfort. Figure $4 \mathrm{~b}$ shows the exponent for pitch input. Here the mean value is 0.47 and the standard deviation is 0.02 . There is hardly any frequency dependence. Similar is the case of roll input (Figure 4c) where the mean is 0.57 and standard deviation of 0.03. Interestingly, the mean values vary significantly depending on the type of input. As the exponent is an indicator of rate of growth of sensation with respect to the input acceleration amplitude, the roll input is most aggressive whereas the pitch input more gradual.

The constant in Stevens' power law is dependent on the scale used to quantify the perception. Figure 5 shows the constants as estimated for all three inputs for varying excitation frequency. All the values are below 10, whereas it has been found to be in the range of 100s for a study (Morioka and Griffin, 2006) where the perception was quantified using a scale of 0 to 100 . The constant, here is highly frequency dependent and appears to follow the weighting described by the standards ISO 2631-1 (1997), for example, in the heave mode of input. The trend is similar to that found on $\mathrm{Z}$ axis in Ref (Morioka and Griffin, 2006). The variation with the frequency is related to the resonances of human body. For the heave input where 4 to $8 \mathrm{~Hz}$ are particularly influenced by resonances, the constants are larger than at other frequencies. Similar patterns based around resonance frequencies are also seen for the roll and pitch inputs. The roll input shows highest values at very low frequencies, which could be due to resonance where occupant upper body acts as a pendulum hinged on the seat surface.

Overall, the Stevens' power law parameters found in this study for heave input are in broad agreement with the published literature. Small deviations could be because of the use of in-situ measurements on a vehicle, in particular the effect of seat cushion. The exponents found for all three inputs are within the range that has been observed in vibration perception. Therefore, the parameters found can be used in predictive models. 


\subsection{Comparative discussion on the dynamic response of 3DOF system}

In this section, frequency responses of 3DOF system of section 2.2.1. are critically compared. Using equation (5), for a harmonic input, vehicle body and wheel hub responses can be calculated. The parameters used for the analysis are listed in Table 1-2 - the values used are typical, resulting in natural frequencies similar to the ones found on vehicles. The top mount behaviour is used in arriving at stiffness for the component (Thite et al, 2017). The input at the wheel is harmonic unit amplitude displacement, with frequency varying from 0 to $30 \mathrm{~Hz}$. The motion transmissibilities were calculated for both models.

Figure $6 \mathrm{~b}$ shows the comparison of vehicle body motion for the suspension damping coefficient of $2000 \mathrm{Ns} / \mathrm{m}$. The effect of series stiffness is evident; the isolation effect after 15 $\mathrm{Hz}$ clearly improves NVH performance. There is counteracting effect at lower frequencies, especially increased contribution from wheel motion, which cannot be neglected for comfort studies. The difference is clearly visible in measured transmissibility on a vehicle as shown in Figure $6 \mathrm{~b}$. The wheel hop mode has transmissibility of $\sim 0.4$ which is much larger than that found using Kelvin-Voigt arrangement. The difference is much more emphatic for wheel motion (Figure 6b), which can significantly influence the tyre contact force, affecting vehicle handling.

The resonance frequencies and associated response amplitudes are a function of both damping coefficient and series stiffness. Figure 7a shows, for the ordinary model, frequency response magnitude of the wheel hub with reference to tyre input, varying as a function of excitation frequency and suspension damping coefficient. There are two clear peaks corresponding to vehicle bounce mode and wheel hop mode. There is a smaller peak due to influence of occupant-seat dynamics. As expected, the increase in damping reduces the resonance frequencies (clear from trace of the peaks) initially, for example the damped wheel hop frequency reduces. For very high damping (not usually seen on vehicles), the relative motion between the wheel and vehicle body reduces to such an extent that eventually one DOF is eliminated from the system. Figure $7 \mathrm{~b}$ shows the corresponding plot for Maxwell model. The wheel hop frequency increases as the damping increases i.e. the effect of series stiffness becomes large and in the limit the effective damping reduces to a negligible value (equation (1)) and a sharp peak occurs at the wheel hop mode. There is a region, where the resonance amplitude becomes smallest for a particular value of damping (in this case for $\sim 1700 \mathrm{Ns} / \mathrm{m}$ ), which can be exploited to improve the performance of vehicle comfort and/or handling. 
Relatively, the effect of change in the suspension damping coefficient on vehicle bounce mode is moderate.

Overall, the resonance frequencies and the effective damping can be very different in the presence of series stiffness. Although, the vehicle model is much complex than the 3 DOF system analysed in this section, ae similar behaviour at wheel hop mode is expected (as seen in Figure 6).

\subsection{Vehicle-occupant dynamic response}

The transmissibility plots are generated for seat-occupant and the vehicle body using parameter values from Table 4. In general, the vehicle motion is coupled i.e. heave, pitch and roll motion of the vehicle occur simultaneously for a given input; the extent of correlation depends on the vehicle parameters. For the vehicle under consideration, for heave input, the transmissibilities of vehicle motion with reference to one of the wheel inputs are shown in Figure $8 \mathrm{a}$. The vehicle has predominant vertical motion but there is some contribution towards vehicle pitch and roll. The vehicle bounce and wheel hop frequencies dominate the transmissibilities. The wheel hop frequency contribution similar to that observed on the vehicle on four-post rig (Figure 6a). Beyond wheel hop frequency, the predicted transmissibility is smaller than from the four post rig tests as higher modes due to structure flexibility such as chassis warp etc., are not considered. The seat-occupant response, apart from the vehicle modes of vibration, is further dependent on the seat dynamics. Figure $8 \mathrm{~b}$ shows transmissibilities related to the seat-occupant motion. There are contributions from vehicle bounce and wheel hop frequencies, and the seat-occupant bounce frequency is resulting in a peak around $9 \mathrm{~Hz}$. The pitch and roll frequencies of the seat-occupant are also excited. Overall, the vertical motion of seat-occupant is dominant for the heave input.

Figure 9a shows response of the vehicle to pitch input. As expected the vehicle pitch mode is excited; as vehicle motion is correlated vehicle bounce and vehicle roll also exist. The pitch angular motion is dominant followed by the vehicle bounce. The presence of vehicle bounce and roll is expected to influence seat-occupant motion. Figure $9 \mathrm{~b}$ shows seat-occupant motion for the given input. The pitch motion is a combination of the vehicle pitch and localized pitch of the seat-occupant. At about $6 \mathrm{~Hz}$, due to contribution from the seat-occupant pitch frequency, transmissibility increases and later at higher frequencies the same feature results in motion isolation. The bounce motion is significant; the larger seat-occupant bounce motion is due to location of the seat away from the centre of gravity. 
Figure 10 shows vehicle motion for the roll input; the roll angular motion dominates the vehicle response. Due to motion correlation, bounce and pitch motion are also present. As in the pitch input, because of the distance between roll centre and location of the seat, seatoccupant bounce motion is induced. The localized roll of seat-occupant is also seen, which results in increased transmissibility around $4 \mathrm{~Hz}$. This resonance frequency also helps motion isolation at higher frequencies as the full system can be considered as a multi-stage isolator where increased degrees of freedom improves isolation at higher frequencies. In fact, the response is inversely proportional to $\omega^{2 n}$, where $n$ is the DOF at higher frequencies.

\subsection{Predicted results for typical road input}

For predicting the discomfort index curves, the input to wheels needs to be chosen. A constant individual wheel input of $0.05 \mathrm{~m} / \mathrm{s}$ is used at each frequency, in pure heave, pitch and roll. The signs of inputs are changed to suit the type of input. Figure 11 shows the acceleration at the seat-occupant position for the given inputs. The responses are dominated by resonances. The wheel hop frequency appears dominantly for heave and pitch input. The acceleration due to roll input shows broad distribution across frequencies; for the pitch input, the accelerations are lowest. In all input cases, the influence of wheel hop is to amplify the motion because of the multiplication effect of frequency (equation (9)). The calculated accelerations can now be combined with the parameters of power law, $p$ and $\chi$ values, to obtain DCI for each frequency. The predicted DCI values are rounded to nearest integer. The resulting DCI variation is shown in Figure 12. The roll input, as expected, results in poor discomfort ratings compared to other inputs. It has large DCI throughout the frequency range. The effects of resonances are clear. The wheel hop frequency ( 12 to $15 \mathrm{~Hz}$ ) contribution is evident in bounce and pitch motion; the effect of including top mount stiffness in the refined model is huge.

The use of DCI curves highlights the effect of vehicle dynamics and can clearly be related to vehicle design parameters. For example, Figure 13 shows the effect of change in vehicle seat parameters of stiffness and damping when heave input is given. The stiffness in vertical direction is reduced to $20 \%$ of the base value listed in Table 4 . The influence of this is to reduce the seat resonance frequency and hence improve the isolation at slightly higher frequencies - which is clear is Figure 13 where the comfort improves after $\sim 6 \mathrm{~Hz}$. The figure also shows further change - the influence of seat damping; here it is increased by $75 \%$ over and above the change in stiffness. Due to increased damping motion transmissibility reduces near the dominant resonance but increases in vibration isolation region of higher frequencies. 
Consequently, there is a slight improvement in comfort between 4 and $6 \mathrm{~Hz}$ but getting poorer performances beyond $\sim 12 \mathrm{~Hz}$. In this case study, therefore, if frequency averaging techniques were used, the effects of resonances won't have been highlighted. Overall, using these curves along with a vehicle-occupant model for a particular vehicle, one can conduct parametric analysis to optimize vehicle with the full knowledge of frequency-based DCI variations.

\section{Conclusions}

An integrated vehicle-occupant model is developed to obtain the occupant response to a given harmonic input. The suspension model was refined to contain the effect of compliance in damper as well as intentionally introduced stiffness in series with damper. Based on the relative stiffness of the spring in series, the resonance frequencies vary. The most significant effect was on the frequency and the amplitude of wheel hop mode. A damping can be found where the amplitude is a minimum; further increase in damping increases the amplitude at resonance and is detrimental to both discomfort due to vibration and vehicle handling.

The Stevens' power law parameters were found for in-situ measured discomfort indices; these parameters were found comparable to earlier studies. The parameters were then used to predict discomfort index for a given sea-occupant acceleration and frequency combination. The frequency variation suggests importance of not just using frequency average discomfort indices while optimizing vehicle suspension and seat parameters. Overall, the model developed along with integration of measured discomfort indices provides a complementary tool to carry out comfort studies during the design of a vehicle.

Acknowledgements: The author would like to thank Alex Fernandez, Dr Luke Bennett, Dr Tulay Ibicek, Fredrick Coleman, Nicola Fisher and Michael Doody for numerous discussions on vehicle dynamics and help with various experiments that contributed towards and enhanced the quality of the paper. 


\section{References}

Bouazara, M. and Richard, M.J. (2001) An optimization method designed to improve 3-D vehicle comfort and road holding capability through the use of active and semi-active suspensions, Journal of Mechanics A/Solids, 20, 509-520.

Bouazara, M., Richard, M.J. and Rakheja, S. (2006) Safety and comfort analysis of a 3-D vehicle model with optimal non-linear active seat suspension, Journal of Terramechanics, 43, 97-118.

Duym, S. (1997) An alternative force state map for shock absorbers, Proceeding of Institution of Mechanical Engineers, Part D: Journal of Automobile Engineering, 211, 175-179.

Gillespie, T. D. (1992) Fundamentals of Vehicle Dynamics, Society of Automotive Engineers, USA.

Griffin, M. J. (1990) Handbook of Human Vibration, Elsevier Academic Press, London.

Griffin, M.J. (2007) Discomfort from Feeling Vehicle Vibration, Vehicle System Dynamics, 45, 679-698.

Hacaambwa TM and Giacomin J. (2007) Subjective response to seated fore-and-aft direction whole-body vibration, International Journal of Industrial Ergonomics, 37, 61-72.

Hegazy, S. and Sandu, C. (2009) Vehicle Ride Comfort and Stability Performance Evaluation, SAE Technical Paper 2009-01-2859.

Ibicek, T. and Thite A.N. (2012), Quantification of human discomfort in a vehicle using a fourpost rig excitation, Journal of low frequency noise, vibration and active control 31, $29-42$.

Ibicek, T. and Thite A.N. (2014) In Situ Measurement of Discomfort Curves for Seated Subjects in a Car on the Four-Post Rig, Advances in Acoustics and Vibration, vol. 2014, Article ID 239178.

ISO 2631-1 (1997) Mechanical vibration and shock: Evaluation of human exposure to wholebody vibration part 1: general requirements, International Organization for Standardization.

Jones, A.J. and Saunders, D.J. (1974) A scale of human reaction to whole body, vertical, sinusoidal vibration, Journal of Sound and Vibration 35, 503-520.

Kubo, M., Terauchi, F., Aoki, H. and Matsuoka, Y. (2001) An investigation into a synthetic vibration model for humans: An investigation into a mechanical vibration human model constructed according to the relations between the physical, psychological and physiological reactions of humans exposed to vibration, International Journal of Industrial Ergonomics, 27, 219-232.

Lingyang, L., Yunqing, Z., Shiwei, W. and Liping, C. (2010) Optimization of suspension elastomeric bushing compliance under constraints of handling, ride and durability, SAE Paper 2010- 01-0721, 2010. 
Milliken, W.F. and Milliken, D.L. (1995) Race Car Vehicle Dynamics, Society of Automotive Engineers, USA.

Miwa, T. (1968) Evaluation methods for vibration effect-part 4. Measurements of vibration greatness for whole-body and hand in vertical and horizontal vibrations, Industrial Health, $6,1-10$.

Morioka, M. and Griffin, M.J. (2006) Magnitude-dependence of equivalent comfort contours for fore-and-aft, lateral and vertical whole-body vibration, Journal of Sound and Vibration, 298, 755-772.

Patil, M.K., Palanicham, M.S. and Ghista, D.N. (1978) Man-tractor system dynamics: Towards a better suspension system for human ride comfort, Journal of Biomechanics, 11, 397406.

Plewa, K., Eger, T., Oliver, M. and Dickey, J. (2012) Comparison between ISO 2631-1 Comfort Prediction Equations and Self-Reported Comfort Values during Occupational Exposure to Whole-Body Vehicular Vibration, Journal of Low frequency noise vibration and active control, 31, 45-53.

Reimpell, J., Stoll, H. and Betzler, J.W. (2001) The Automotive Chassis: Engineering Principles, 2nd Edition, Butterworth-Heinman.

Simms, A. and Crolla, D. (2002) The Influence of Damper Properties on Vehicle Dynamic Behaviour, SAE 2002-01-0319.

Stevens, S.S. (1975). Psychophysics: introduction to its perceptual, neural, and social prospects, Wiley, New York, 1975.

Thite, AN., Banvidi, S., Ibicek, T. and Bennett L (2011). Suspension parameter estimation in the frequency domain using a matrix inversion approach, Vehicle System Dynamics 49, $12,1803-1822$.

Thite, A.N., Coleman, F., Doody, M. and Fisher, N. (2017). Experimentally validated dynamic results of a relaxation type quarter car suspension with an adjustable damper, Journal of Low Frequency Noise, Vibration and Active Control, 36 (2), 148-159.

Yang, X. and Medepalli, S. (2005) Sensitivities of suspension bushings on vehicle impact harshness performances, Technical Paper 2005-01-0827.

Yang, X., Zhang, D., Medapalli, S. and Malik, M. (2006) Suspension tuning parameters affecting impact harshness performance evaluation, SAE Paper, 2006-01-0991. 


\section{APPENDIX}

\section{Occupant model}

Occupant vertical motion

$$
\begin{gathered}
m_{\mathrm{o}} \ddot{z}+\left(c_{\mathrm{fs} 1}+c_{\mathrm{fs} 2}+c_{\mathrm{fs} 3}+c_{\mathrm{fs} 4}\right) \dot{z}+\left(k_{\mathrm{fs} 1}+k_{\mathrm{fs} 2}+k_{\mathrm{fs} 3}+k_{\mathrm{fs} 4}\right) z+\left(c_{\mathrm{fs} 1}-c_{\mathrm{fs} 2}-c_{\mathrm{fs} 3}+c_{\mathrm{fs} 4}\right) r_{\mathrm{p}} \dot{\alpha} \\
+\left(k_{\mathrm{fs} 1}-k_{\mathrm{fs} 2}-k_{\mathrm{fs} 3}+k_{\mathrm{fs} 4}\right) r_{\mathrm{p}} \alpha+\left(-c_{\mathrm{fs} 1}-c_{\mathrm{fs} 2}+c_{\mathrm{fs} 3}+c_{\mathrm{fs} 4}\right) r_{\mathrm{r}} \dot{\beta}+\left(-k_{\mathrm{fs} 1}-k_{\mathrm{fs} 2}+k_{\mathrm{fs} 3}+k_{\mathrm{fs} 4}\right) r_{\mathrm{r}} \beta \\
-\left(c_{\mathrm{fs} 1}+c_{\mathrm{fs} 2}+c_{\mathrm{fs} 3}+c_{\mathrm{fs} 4}\right) \dot{x}-\left(k_{\mathrm{fs} 1}+k_{\mathrm{fs} 2}+k_{\mathrm{fs} 3}+k_{\mathrm{fs} 4}\right) x \\
-\left(\left(c_{\mathrm{fs} 1}+c_{\mathrm{fs} 4}\right)\left(l_{\mathrm{s} 1}+r_{\mathrm{p}}\right)+\left(c_{\mathrm{fs} 2}+c_{\mathrm{fs} 3}\right)\left(l_{\mathrm{s} 1}-r_{\mathrm{p}}\right)\right) \dot{\theta} \\
-\left(\left(k_{\mathrm{fs} 1}+k_{\mathrm{fs} 4}\right)\left(l_{\mathrm{s} 1}+r_{\mathrm{p}}\right)+\left(k_{\mathrm{fs} 2}+k_{\mathrm{fs} 3}\right)\left(l_{\mathrm{s} 1}-r_{\mathrm{p}}\right)\right) \theta \\
-\left(\left(c_{\mathrm{fs} 1}+c_{\mathrm{fs} 2}\right)\left(l_{\mathrm{s} 2}-r_{\mathrm{r}}\right)+\left(c_{\mathrm{fs} 3}+c_{\mathrm{fs} 4}\right)\left(l_{\mathrm{s} 2}+r_{\mathrm{r}}\right)_{\mathrm{r}}\right) \dot{\phi} \\
-\left(\left(k_{\mathrm{fs} 1}+k_{\mathrm{fs} 2}\right)\left(l_{\mathrm{s} 2}-r_{\mathrm{r}}\right)+\left(k_{\mathrm{fs} 3}+k_{\mathrm{fs} 4}\right)\left(l_{\mathrm{s} 2}+r_{\mathrm{r}}\right)_{\mathrm{r}}\right) \phi=0
\end{gathered}
$$

Occupant pitch

$$
\begin{aligned}
& I_{\mathrm{op}} \ddot{\alpha}+\left(c_{\mathrm{fs} 1}-c_{\mathrm{fs} 2}-c_{\mathrm{fs} 3}+c_{\mathrm{fs} 4}\right) r_{\mathrm{p}} \dot{z}+\left(k_{\mathrm{fs} 1}-k_{\mathrm{fs} 2}-k_{\mathrm{fs} 3}+k_{\mathrm{fs} 4}\right) r_{\mathrm{p}} z+\left(c_{\mathrm{fs} 1}+c_{\mathrm{fs} 2}+c_{\mathrm{fs} 3}+c_{\mathrm{fs} 4}+c_{t s p} / r_{\mathrm{p}}^{2}\right) r_{\mathrm{p}}^{2} \dot{\alpha} \\
& +\left(k_{\mathrm{fs} 1}+k_{\mathrm{fs} 2}+k_{\mathrm{fs} 3}+k_{\mathrm{fs} 4}+k_{t s p} / r_{\mathrm{p}}^{2}\right) r_{\mathrm{p}}^{2} \alpha+\left(-c_{\mathrm{fs} 1}+c_{\mathrm{fs} 2}-c_{\mathrm{fs} 3}+c_{\mathrm{fs} 4}\right) r_{\mathrm{p}} r_{\mathrm{r}} \dot{\beta}+\left(-k_{\mathrm{fs} 1}+k_{\mathrm{fs} 2}-k_{\mathrm{fs} 3}+k_{\mathrm{fs} 4}\right) r_{\mathrm{p}} r_{\mathrm{r}} \beta \\
& \quad-\left(c_{\mathrm{fs} 1}-c_{\mathrm{fs} 2}-c_{\mathrm{fs} 3}+c_{\mathrm{fs} 4}\right) r_{\mathrm{p}} \dot{x}-\left(k_{\mathrm{fs} 1}-k_{\mathrm{fs} 2}-k_{\mathrm{fs} 3}+k_{\mathrm{fs} 4}\right) r_{\mathrm{p}} x-\left(\left(c_{\mathrm{fs} 1}+c_{\mathrm{fs} 4}\right)\left(l_{\mathrm{s} 1}+r_{\mathrm{p}}\right)-\left(c_{\mathrm{fs} 2}+c_{\mathrm{fs} 3}\right)\left(l_{\mathrm{s} 1}-r_{\mathrm{p}}\right)+c_{t s p} / r_{\mathrm{p}}\right) r_{\mathrm{p}} \dot{\theta} \\
& \quad-\left(\left(k_{\mathrm{fs} 1}+k_{\mathrm{fs} 4}\right)\left(l_{\mathrm{s} 1}+r_{\mathrm{p}}\right)-\left(k_{\mathrm{fs} 2}+k_{\mathrm{fs} 3}\right)\left(l_{\mathrm{s} 1}-r_{\mathrm{p}}\right)+k_{t s p} / r_{\mathrm{p}}\right) r_{\mathrm{p}} \theta-\left(\left(c_{\mathrm{fs} 1}-c_{\mathrm{fs} 2}\right)\left(l_{\mathrm{s} 2}-r_{\mathrm{r}}\right)-\left(c_{\mathrm{fs} 3}-c_{\mathrm{fs} 4}\right)\left(l_{\mathrm{s} 2}+r_{\mathrm{r}}\right)\right) r_{\mathrm{p}} \dot{\phi} \\
& \quad \\
& \quad-\left(\left(k_{\mathrm{fs} 1}-k_{\mathrm{fs} 2}\right)\left(l_{\mathrm{s} 2}-r_{\mathrm{r}}\right)-\left(k_{\mathrm{fs} 3}-k_{\mathrm{fs} 4}\right)\left(l_{\mathrm{s} 2}+r_{\mathrm{r}}\right)\right) r_{\mathrm{p}} \phi=0
\end{aligned}
$$

Occupant roll

$$
\begin{gathered}
I_{\mathrm{or}} \ddot{\beta}+\left(-c_{\mathrm{fs} 1}-c_{\mathrm{fs} 2}+c_{\mathrm{fs} 3}+c_{\mathrm{fs} 4}\right) r_{\mathrm{r}} \dot{z}+\left(-k_{\mathrm{fs} 1}-k_{\mathrm{fs} 2}+k_{\mathrm{fs} 3}+k_{\mathrm{fs} 4}\right) r_{\mathrm{r}} z+\left(-c_{\mathrm{fs} 1}+c_{\mathrm{fs} 2}-c_{\mathrm{fs} 3}+c_{\mathrm{fs} 4}\right) r_{\mathrm{p}} r_{\mathrm{r}} \dot{\alpha} \\
+\left(-k_{\mathrm{fs} 1}+k_{\mathrm{fs} 2}-k_{\mathrm{fs} 3}+k_{\mathrm{fs} 4}\right) r_{\mathrm{p}} r_{\mathrm{r}} \alpha+\left(c_{\mathrm{fs} 1}+c_{\mathrm{fs} 2}+c_{\mathrm{fs} 3}+c_{\mathrm{fs} 4}+c_{t s r} / r_{\mathrm{r}}^{2}\right) r_{\mathrm{r}}^{2} \dot{\beta} \\
+\left(k_{\mathrm{fs} 1}+k_{\mathrm{fs} 2}+k_{\mathrm{fs} 3}+k_{\mathrm{fs} 4}+k_{\mathrm{tsr}} / r_{\mathrm{r}}^{2}\right) r_{\mathrm{r}}^{2} \beta-\left(c_{\mathrm{fs} 1}+c_{\mathrm{fs} 2}-c_{\mathrm{fs} 3}-c_{\mathrm{fs} 4}\right) r_{\mathrm{r}} \dot{x}-\left(k_{\mathrm{fs} 1}+k_{\mathrm{fs} 2}-k_{\mathrm{fs} 3}-k_{\mathrm{fs} 4}\right) r_{\mathrm{r}} x \\
-\left(c_{\mathrm{fs} 1}\left(l_{\mathrm{s} 1}+r_{\mathrm{p}}\right)+c_{\mathrm{fs} 2}\left(l_{\mathrm{s} 1}-r_{\mathrm{p}}\right)-c_{\mathrm{fs} 3}\left(l_{\mathrm{s} 1}-r_{\mathrm{p}}\right)-c_{\mathrm{fs} 4}\left(l_{\mathrm{s} 1}+r_{\mathrm{p}}\right)\right) r_{\mathrm{r}} \dot{\theta} \\
-\left(k_{\mathrm{fs} 1}\left(l_{\mathrm{s} 1}+r_{\mathrm{p}}\right)+k_{\mathrm{fs} 2}\left(l_{\mathrm{s} 1}-r_{\mathrm{p}}\right)-k_{\mathrm{fs} 3}\left(l_{\mathrm{s} 1}-r_{\mathrm{p}}\right)-k_{\mathrm{fs} 4}\left(l_{\mathrm{s} 1}+r_{\mathrm{p}}\right)\right) r_{\mathrm{r}} \theta \\
\quad-\left(\left(c_{\mathrm{fs} 1}+c_{\mathrm{fs} 2}\right)\left(l_{\mathrm{s} 2}-r_{\mathrm{r}}\right)-\left(c_{\mathrm{fs} 3}+c_{\mathrm{fs} 4}\right)\left(l_{\mathrm{s} 2}+r_{\mathrm{r}}\right)+c_{t s r} / r_{\mathrm{r}}\right) r_{\mathrm{r}} \dot{\phi} \\
-\left(\left(k_{\mathrm{fs} 1}+k_{\mathrm{fs} 2}\right)\left(l_{\mathrm{s} 2}-r_{\mathrm{r}}\right)-\left(k_{\mathrm{fs} 3}+k_{\mathrm{fs} 4}\right)\left(l_{\mathrm{s} 2}+r_{\mathrm{r}}\right)+k_{t s r} / r_{\mathrm{r}}\right) r_{\mathrm{r}} \phi=0
\end{gathered}
$$




\section{Vehicle model considering influence of the occupant}

Body heave

$$
\begin{aligned}
& m_{v} \ddot{x}+\left(c_{\mathrm{fs} 1}+c_{\mathrm{fs} 2}+c_{\mathrm{fs} 3}+c_{\mathrm{fs} 4}\right) \dot{x}+\left(k_{\mathrm{sus} 1}+k_{\mathrm{d} 1}+k_{\mathrm{sus} 2}+k_{\mathrm{d} 2}+k_{\mathrm{sus} 3}+k_{\mathrm{d} 3}+k_{\mathrm{sus} 4}+k_{\mathrm{d} 4}+k_{\mathrm{fs} 1}+k_{\mathrm{fs} 2}+k_{\mathrm{fs} 3}+k_{\mathrm{fs} 4}\right) x \\
& +\left(\left(c_{\mathrm{fs} 1}+c_{\mathrm{fs} 4}\right)\left(l_{\mathrm{s} 1}+r_{\mathrm{p}}\right)+\left(c_{\mathrm{fs} 2}+c_{\mathrm{fs} 3}\right)\left(l_{\mathrm{s} 1}-r_{\mathrm{p}}\right)\right) \dot{\theta} \\
& +\left(\left(k_{\mathrm{sus} 1}+k_{\mathrm{d} 1}+k_{\mathrm{sus} 4}+k_{\mathrm{d} 4}\right) l_{1}-\left(k_{\mathrm{sus} 2}+k_{\mathrm{d} 2}+k_{\mathrm{sus} 3}+k_{\mathrm{d} 3}\right) l_{2}+\left(k_{\mathrm{fs} 1}+k_{\mathrm{fs} 4}\right)\left(l_{\mathrm{s} 1}+r_{\mathrm{p}}\right)+\left(k_{\mathrm{fs} 2}+k_{\mathrm{fs} 3}\right)\left(l_{\mathrm{s} 1}-r_{\mathrm{p}}\right)\right) \theta \\
& +\left(\left(c_{\mathrm{fs} 1}+c_{\mathrm{fs} 2}\right)\left(l_{\mathrm{s} 2}-r_{r}\right)+\left(c_{\mathrm{fs} 3}+c_{\mathrm{fs} 4}\right)\left(l_{\mathrm{s} 2}+r_{r}\right)\right) \dot{\phi} \\
& +\left(\left(k_{\mathrm{sus} 3}+k_{\mathrm{d} 3}+k_{\mathrm{sus} 4}+k_{\mathrm{d} 4}\right) b_{1}-\left(k_{\mathrm{sus} 1}+k_{\mathrm{d} 1}+k_{\mathrm{sus} 2}+k_{\mathrm{d} 2}\right) b_{2}+\left(k_{\mathrm{fs} 1}+k_{\mathrm{fs} 2}\right)\left(l_{\mathrm{s} 2}-r_{r}\right)+\left(k_{\mathrm{fs} 3}+k_{\mathrm{fs} 4}\right)\left(l_{\mathrm{s} 2}+r_{r}\right)\right) \phi \\
& -k_{\mathrm{su} 1} x_{5}-k_{\mathrm{sus} 2} x_{6}-k_{\mathrm{sus} 3} x_{7}-k_{\mathrm{sus} 4} x_{8}-k_{\mathrm{d} 1} x_{9}-k_{\mathrm{d} 2} x_{10}-k_{\mathrm{d} 3} x_{11}-k_{\mathrm{d} 4} x_{12} \\
& -\left(c_{\mathrm{fs} 1}+c_{\mathrm{fs} 2}+c_{\mathrm{fs} 3}+c_{\mathrm{fs} 4}\right) \dot{z}+\left(-c_{\mathrm{fs} 1}+c_{\mathrm{fs} 2}+c_{\mathrm{fs} 3}-c_{\mathrm{fs} 4}\right) r_{\mathrm{p}} \dot{\alpha}+\left(c_{\mathrm{fs} 1}+c_{\mathrm{fs} 2}-c_{\mathrm{fs} 3}-c_{\mathrm{fs} 4}\right) r_{\mathrm{r}} \dot{\beta} \\
& -\left(k_{\mathrm{fs} 1}+k_{\mathrm{fs} 2}+k_{\mathrm{fs} 3}+k_{\mathrm{fs} 4}\right) z+\left(-k_{\mathrm{fs} 1}+k_{\mathrm{fs} 2}+k_{\mathrm{fs} 3}-k_{\mathrm{fs} 4}\right) r_{\mathrm{p}} \alpha+\left(k_{\mathrm{fs} 1}+k_{\mathrm{fs} 2}-k_{\mathrm{fs} 3}-k_{\mathrm{fs} 4}\right) r_{\mathrm{r}} \beta=0
\end{aligned}
$$

Body pitch

$$
\begin{aligned}
& I_{\mathrm{p}} \ddot{\theta}+\left(\left(c_{\mathrm{fs} 1}+c_{\mathrm{fs} 2}+c_{\mathrm{fs} 3}+c_{\mathrm{fs} 4}\right) l_{\mathrm{s} 1}+\left(c_{\mathrm{fs} 1}-c_{\mathrm{fs} 2}-c_{\mathrm{fs} 3}+c_{\mathrm{fs} 4}\right) r_{\mathrm{p}}\right) \dot{x} \\
& +\left(\left(k_{\mathrm{sus} 1}+k_{\mathrm{d} 1}+k_{\mathrm{sus} 4}+k_{\mathrm{d} 4}\right) l_{1}-\left(k_{\mathrm{sus} 2}+k_{\mathrm{d} 2}+k_{\mathrm{sus} 3}+k_{\mathrm{d} 3}\right) l_{2}+\left(k_{\mathrm{fs} 1}+k_{\mathrm{fs} 2}+k_{\mathrm{fs} 3}+k_{\mathrm{fs} 4}\right) l_{\mathrm{s} 1}+\left(k_{\mathrm{fs} 1}-k_{\mathrm{fs} 2}-k_{\mathrm{fs} 3}+k_{\mathrm{fs} 4}\right) r_{\mathrm{p}}\right) x \\
& +\left(\left(c_{\mathrm{fs} 1}+c_{\mathrm{fs} 4}\right)\left(l_{\mathrm{s} 1}+r_{\mathrm{p}}\right)^{2}+\left(c_{\mathrm{fs} 2}+c_{\mathrm{fs} 3}\right)\left(l_{\mathrm{s} 1}-r_{\mathrm{p}}\right)^{2}+c_{t s p}\right) \dot{\theta} \\
& +\left(\left(k_{\mathrm{sus} 1}+k_{\mathrm{d} 1}+k_{\mathrm{sus} 4}+k_{\mathrm{d} 4}\right) l_{1}^{2}+\left(k_{\mathrm{sus} 2}+k_{\mathrm{d} 2}+k_{\mathrm{sus} 3}+k_{\mathrm{d} 3}\right) l_{2}^{2}+\left(k_{\mathrm{fs} 1}+k_{\mathrm{fs} 4}\right)\left(l_{\mathrm{s} 1}+r_{\mathrm{p}}\right)^{2}+\left(k_{\mathrm{fs} 2}+k_{\mathrm{fs} 3}\right)\left(l_{\mathrm{s} 1}-r_{\mathrm{p}}\right)^{2}+k_{t s p}\right) \theta \\
& +\left(\left(c_{\mathrm{fs} 1}\left(l_{\mathrm{s} 1}+r_{\mathrm{p}}\right)+c_{\mathrm{fs} 2}\left(l_{\mathrm{s} 1}-r_{\mathrm{p}}\right)\right)\left(l_{\mathrm{s} 2}-r_{r}\right)+\left(c_{\mathrm{fs} 3}\left(l_{\mathrm{s} 1}-r_{\mathrm{p}}\right)+c_{\mathrm{fs} 4}\left(l_{\mathrm{s} 1}+r_{\mathrm{p}}\right)\right)\left(l_{\mathrm{s} 2}+r_{r}\right)\right) \dot{\phi} \\
& +\left(-\left(k_{\text {sus } 1}+k_{\mathrm{d} 1}\right) l_{1} b_{2}+\left(k_{\text {sus } 2}+k_{\mathrm{d} 2}\right) l_{2} b_{2}-\left(k_{\text {sus } 3}+k_{\mathrm{d} 3}\right) l_{2} b_{1}+\left(k_{\text {sus } 4}+k_{\mathrm{d} 4}\right) l_{1} b_{1}\right) \phi \\
& +\left(\left(k_{\mathrm{fs} 1}\left(l_{\mathrm{s} 1}+r_{\mathrm{p}}\right)+k_{\mathrm{fs} 2}\left(l_{\mathrm{s} 1}-r_{\mathrm{p}}\right)\right)\left(l_{\mathrm{s} 2}-r_{r}\right)+\left(k_{\mathrm{fs} 3}\left(l_{\mathrm{s} 1}-r_{\mathrm{p}}\right)+k_{\mathrm{fs} 4}\left(l_{\mathrm{s} 1}+r_{\mathrm{p}}\right)\right)\left(l_{\mathrm{s} 2}+r_{r}\right)\right) \phi \\
& -k_{\text {sus } 1} l_{1} x_{5}+k_{\text {sus } 2} l_{2} x_{6}+k_{\text {sus } 3} l_{2} x_{7}-k_{\text {sus } 4} l_{1} x_{8}-k_{\mathrm{d} 1} l_{1} x_{9}+k_{\mathrm{d} 2} l_{2} x_{10}+k_{\mathrm{d} 3} l_{2} x_{11}-k_{\mathrm{d} 4} l_{1} x_{12} \\
& -\left(\left(c_{\mathrm{fs} 1}+c_{\mathrm{fs} 4}\right)\left(l_{\mathrm{s} 1}+r_{\mathrm{p}}\right)+\left(c_{\mathrm{fs} 2}+c_{\mathrm{fs} 3}\right)\left(l_{\mathrm{s} 1}-r_{\mathrm{p}}\right)\right) \dot{z}+\left(-\left(c_{\mathrm{fs} 1}+c_{\mathrm{fs} 4}\right)\left(l_{\mathrm{s} 1}+r_{\mathrm{p}}\right)+\left(c_{\mathrm{fs} 2}+c_{\mathrm{fs} 3}\right)\left(l_{\mathrm{s} 1}-r_{\mathrm{p}}\right)-c_{t s p} / r_{\mathrm{p}}\right) r_{\mathrm{p}} \dot{\alpha} \\
& +\left(\left(c_{\mathrm{fs} 1}-c_{\mathrm{fs} 4}\right)\left(l_{\mathrm{s} 1}+r_{\mathrm{p}}\right)+\left(c_{\mathrm{fs} 2}-c_{\mathrm{fs} 3}\right)\left(l_{\mathrm{s} 1}-r_{\mathrm{p}}\right)\right) r_{\mathrm{r}} \dot{\beta} \\
& -\left(\left(k_{\mathrm{fs} 1}+k_{\mathrm{fs} 4}\right)\left(l_{\mathrm{s} 1}+r_{\mathrm{p}}\right)+\left(k_{\mathrm{fs} 2}+k_{\mathrm{fs} 3}\right)\left(l_{\mathrm{s} 1}-r_{\mathrm{p}}\right)\right) z+\left(-\left(k_{\mathrm{fs} 1}+k_{\mathrm{fs} 4}\right)\left(l_{\mathrm{s} 1}+r_{\mathrm{p}}\right)+\left(k_{\mathrm{fs} 2}+k_{\mathrm{fs} 3}\right)\left(l_{\mathrm{s} 1}-r_{\mathrm{p}}\right)-k_{t s p} / r_{\mathrm{p}}\right) r_{\mathrm{p}} \alpha \\
& +\left(\left(k_{\mathrm{fs} 1}-k_{\mathrm{fs} 4}\right)\left(l_{\mathrm{s} 1}+r_{\mathrm{p}}\right)+\left(k_{\mathrm{fs} 2}-k_{\mathrm{fs} 3}\right)\left(l_{\mathrm{s} 1}-r_{\mathrm{p}}\right)\right) r_{\mathrm{r}} \beta=0
\end{aligned}
$$




\section{Body roll}

$$
\begin{aligned}
& I_{\mathrm{r}} \ddot{\phi}+\left(\left(c_{\mathrm{fs} 1}+c_{\mathrm{fs} 2}\right)\left(l_{\mathrm{s} 2}-r_{r}\right)+\left(c_{\mathrm{fs} 3}+c_{\mathrm{fs} 4}\right)\left(l_{\mathrm{s} 2}+r_{r}\right)\right) \dot{x} \\
& +\left(-\left(k_{\mathrm{sus} 1}+k_{\mathrm{d} 1}+k_{\mathrm{su} 2}+k_{\mathrm{d} 2}\right) b_{2}+\left(k_{\mathrm{sus} 3}+k_{\mathrm{d} 3}+k_{\mathrm{sus} 4}+k_{\mathrm{d} 4}\right) b_{1}+\left(k_{\mathrm{fs} 1}+k_{\mathrm{fs} 2}\right)\left(l_{\mathrm{s} 2}-r_{r}\right)+\left(k_{\mathrm{fs} 3}+k_{\mathrm{fs} 4}\right)\left(l_{\mathrm{s} 2}+r_{r}\right)\right) x \\
& +\left(\left(c_{\mathrm{fs} 1}\left(l_{\mathrm{s} 1}+r_{\mathrm{p}}\right)+c_{\mathrm{fs} 2}\left(l_{\mathrm{s} 1}-r_{\mathrm{p}}\right)\right)\left(l_{\mathrm{s} 2}-r_{r}\right)+\left(c_{\mathrm{f} 3}\left(l_{\mathrm{s} 1}-r_{\mathrm{p}}\right)+c_{\mathrm{fs} 4}\left(l_{\mathrm{s} 1}+r_{\mathrm{p}}\right)\right)\left(l_{\mathrm{s} 2}+r_{r}\right)\right) \dot{\theta} \\
& +\left(-\left(k_{\text {sus } 1}+k_{\mathrm{d} 1}\right) l_{1} b_{2}+\left(k_{\text {sus } 2}+k_{\mathrm{d} 2}\right) l_{2} b_{2}-\left(k_{\text {sus } 3}+k_{\mathrm{d} 3}\right) l_{2} b_{1}+\left(k_{\text {sus } 4}+k_{\mathrm{d} 4}\right) l_{1} b_{1}\right) \theta \\
& +\left(\left(k_{\mathrm{fs} 1}\left(l_{\mathrm{s} 1}+r_{\mathrm{p}}\right)+k_{\mathrm{fs} 2}\left(l_{\mathrm{s} 1}-r_{\mathrm{p}}\right)\right)\left(l_{\mathrm{s} 2}-r_{r}\right)+\left(k_{\mathrm{fs} 3}\left(l_{\mathrm{s} 1}-r_{\mathrm{p}}\right)+k_{\mathrm{fs} 4}\left(l_{\mathrm{s} 1}+r_{\mathrm{p}}\right)\right)\left(l_{\mathrm{s} 2}+r_{r}\right)\right) \theta \\
& +\left(\left(c_{\mathrm{fs} 1}+c_{\mathrm{fs} 2}\right)\left(l_{\mathrm{s} 2}-r_{r}\right)^{2}+\left(c_{\mathrm{fs} 3}+c_{\mathrm{fs} 4}\right)\left(l_{\mathrm{s} 2}+r_{r}\right)^{2}+c_{t s r}\right) \dot{\phi} \\
& +\left(\left(k_{\mathrm{sus} 1}+k_{\mathrm{d} 1}+k_{\mathrm{sus} 2}+k_{\mathrm{d} 2}\right) b_{2}^{2}+\left(k_{\mathrm{sus} 3}+k_{\mathrm{d} 3}+k_{\mathrm{sus} 4}+k_{\mathrm{d} 4}\right) b_{1}^{2}+\left(k_{\mathrm{fs} 1}+k_{\mathrm{fs} 2}\right)\left(l_{\mathrm{s} 2}-r_{r}\right)^{2}+\left(k_{\mathrm{fs} 3}+k_{\mathrm{fs} 4}\right)\left(l_{\mathrm{s} 2}+r_{r}\right)^{2}+k_{t s r}\right) \phi \\
& +k_{\text {sus } 1} b_{2} x_{5}+k_{\text {sus } 2} b_{2} x_{6}-k_{\text {sus } 3} b_{1} x_{7}-k_{\text {sus } 4} b_{1} x_{8}+k_{\mathrm{d} 1} b_{2} x_{9}+k_{\mathrm{d} 2} b_{2} x_{10}-k_{\mathrm{d} 3} b_{1} x_{11}-k_{\mathrm{d} 4} b_{1} x_{12} \\
& -\left(\left(c_{\mathrm{fs} 1}+c_{\mathrm{fs} 2}\right)\left(l_{\mathrm{s} 2}-r_{r}\right)+\left(c_{\mathrm{fs} 3}+c_{\mathrm{fs} 4}\right)\left(l_{\mathrm{s} 2}+r_{r}\right)\right) \dot{z}-\left(\left(c_{\mathrm{fs} 1}-c_{\mathrm{fs} 2}\right)\left(l_{\mathrm{s} 2}-r_{r}\right)+\left(c_{\mathrm{fs} 3}-c_{\mathrm{fs} 4}\right)\left(l_{\mathrm{s} 2}+r_{r}\right)\right) r_{p} \dot{\alpha} \\
& -\left(\left(c_{\mathrm{fs} 1}+c_{\mathrm{fs} 2}\right)\left(l_{\mathrm{s} 2}-r_{r}\right)-\left(c_{\mathrm{fs} 3}+c_{\mathrm{fs} 4}\right)\left(l_{\mathrm{s} 2}+r_{r}\right)+c_{t s r} / r_{\mathrm{r}}\right) r_{\mathrm{r}} \dot{\beta} \\
& -\left(\left(k_{\mathrm{fs} 1}+k_{\mathrm{fs} 2}\right)\left(l_{\mathrm{s} 2}-r_{r}\right)+\left(k_{\mathrm{fs} 3}+k_{\mathrm{fs} 4}\right)\left(l_{\mathrm{s} 2}+r_{r}\right)\right) z-\left(\left(k_{\mathrm{fs} 1}-k_{\mathrm{fs} 2}\right)\left(l_{\mathrm{s} 2}-r_{r}\right)+\left(k_{\mathrm{fs} 3}-k_{\mathrm{fs} 4}\right)\left(l_{\mathrm{s} 2}+r_{r}\right)\right) r_{p} \alpha \\
& -\left(\left(k_{\mathrm{fs} 1}+k_{\mathrm{fs} 2}\right)\left(l_{\mathrm{s} 2}-r_{r}\right)-\left(k_{\mathrm{fs} 3}+k_{\mathrm{fs} 4}\right)\left(l_{\mathrm{s} 2}+r_{r}\right)+k_{t s r} / r_{\mathrm{r}}\right) r_{\mathrm{r}} \beta=0
\end{aligned}
$$

\section{Motion of unsprung mass}

$$
\begin{aligned}
& m_{\mathrm{u} 1} \ddot{x}_{5}+c_{1} \dot{x}_{5}+\left(k_{\mathrm{t} 1}+k_{\mathrm{sus} 1}\right) x_{5}-c_{1} \dot{x}_{9}-k_{\text {sus } 1}\left(x-b_{2} \phi+l_{1} \theta\right)-k_{\mathrm{t} 1} x_{1}=0 \\
& c_{1} \dot{x}_{9}+k_{\mathrm{d} 1} x_{9}=c_{1} \dot{x}_{5}+k_{\mathrm{d} 1}\left(x-b_{2} \phi+l_{1} \theta\right) \\
& -k_{\mathrm{d} 1} x-k_{\mathrm{d} 1} l_{1} \theta+k_{\mathrm{d} 1} b_{2} \phi-c_{1} \dot{x}_{5}+c_{1} \dot{x}_{9}+k_{\mathrm{d} 1} x_{9}=0 \\
& m_{\mathrm{u} 2} \ddot{x}_{6}+c_{2} \dot{x}_{6}+\left(k_{\mathrm{t} 2}+k_{\mathrm{sus} 2}\right) x_{6}-c_{2} \dot{x}_{10}-k_{\mathrm{sus} 2} x_{14}-k_{\mathrm{t} 2} x_{2}-\frac{k_{\mathrm{roll}}}{b^{2}}\left(x_{7}-x_{6}\right)=0 \\
& \Rightarrow m_{\mathrm{u} 2} \ddot{x}_{6}+c_{2} \dot{x}_{6}+\left(k_{\mathrm{t} 2}+k_{\mathrm{sus} 2}\right) x_{6}+\frac{k_{\mathrm{roll}}}{b^{2}} x_{6}-c_{2} \dot{x}_{10}-k_{\text {sus } 2}\left(x-b_{2} \phi-l_{2} \theta\right)-k_{\mathrm{t} 2} x_{2}-\frac{k_{\mathrm{roll}}}{b^{2}} x_{7}=0 \\
& c_{2} \dot{x}_{10}+k_{\mathrm{d} 2} x_{10}=c_{2} \dot{x}_{6}+k_{\mathrm{d} 2}\left(x-b_{2} \phi-l_{2} \theta\right) \\
& -k_{\mathrm{d} 2} x+k_{\mathrm{d} 2} l_{2} \theta+k_{\mathrm{d} 2} b_{2} \phi-c_{2} \dot{x}_{6}+c_{2} \dot{x}_{10}+k_{\mathrm{d} 2} x_{10}=0 \\
& m_{\mathrm{u} 3} \ddot{x}_{7}+c_{3} \dot{x}_{7}+\left(k_{\mathrm{t} 3}+k_{\mathrm{sus} 3}\right) x_{7}-c_{3} \dot{x}_{11}-k_{\mathrm{sus} 3} x_{15}-k_{\mathrm{t} 3} x_{3}+\frac{k_{\mathrm{roll}}}{b^{2}}\left(x_{7}-x_{6}\right)=0 \\
& \Rightarrow m_{\mathrm{u} 3} \ddot{x}_{7}+c_{3} \dot{x}_{7}+\left(k_{\mathrm{t} 3}+k_{\text {sus } 3}\right) x_{7}+\frac{k_{\text {roll }}}{b^{2}} x_{7}-c_{3} \dot{x}_{11}-k_{\text {sus3 }}\left(x+b_{1} \phi-l_{2} \theta\right)-k_{\mathrm{t} 3} x_{3}-\frac{k_{\text {roll }}}{b^{2}} x_{6}=0 \\
& c_{3} \dot{x}_{11}+k_{\mathrm{d} 3} x_{11}=c_{3} \dot{x}_{7}+k_{\mathrm{d} 3}\left(x+b_{1} \phi-l_{2} \theta\right) \\
& -k_{\mathrm{d} 3} x+k_{\mathrm{d} 3} l_{2} \theta-k_{\mathrm{d} 3} b_{1} \phi-c_{3} \dot{x}_{7}+c_{3} \dot{x}_{11}+k_{\mathrm{d} 3} x_{11}=0 \\
& m_{\mathrm{u} 4} \ddot{x}_{8}+c_{4} \dot{x}_{8}+\left(k_{\mathrm{t} 4}+k_{\mathrm{sus} 4}\right) x_{8}-c_{4} \dot{x}_{12}-k_{\mathrm{sus} 4}\left(x+b_{1} \phi+l_{1} \theta\right)-k_{\mathrm{t} 4} x_{4}=0 \\
& c_{4} \dot{x}_{12}+k_{\mathrm{d} 4} x_{12}=c_{4} \dot{x}_{8}+k_{\mathrm{d} 4}\left(x+b_{1} \phi+l_{1} \theta\right) \\
& -k_{\mathrm{d} 4} x-k_{\mathrm{d} 4} l_{1} \theta-k_{\mathrm{d} 4} b_{1} \phi-c_{4} \dot{x}_{8}+c_{4} \dot{x}_{12}+k_{\mathrm{d} 4} x_{12}=0
\end{aligned}
$$


Table 1. Parameter values used in ordinary quarter car with occupant.

\section{System parameter}

Parameter value

\section{Vehicle parameters}

Tyre stiffness $(\mathrm{N} / \mathrm{m})$

$1.6 \mathrm{e} 5$

Suspension stiffness $(\mathrm{N} / \mathrm{m})$

$4.8 \mathrm{e} 4$

Suspension damping (Ns/m)

varying

Hub mass, front $(\mathrm{kg})$

Vehicle body mass $(\mathrm{kg})$

Occupant and seat parameters

Occupant and seat mass $(\mathrm{kg})$

Occupant and seat bounce stiffness $(\mathrm{N} / \mathrm{m})$ 
Table 2. Parameter values used in compliant member in series quarter car with occupant.

\section{System parameter}

Parameter value

\section{Vehicle parameters}

Tyre stiffness $(\mathrm{N} / \mathrm{m})$

$1.6 \mathrm{e} 5$

Suspension stiffness, front $(\mathrm{N} / \mathrm{m})$

$4.8 \mathrm{e} 4$

Suspension stiffness in series, front $(\mathrm{N} / \mathrm{m})$

$1.6 \mathrm{e} 5$

Suspension damping, rear $(\mathrm{N} / \mathrm{m})$

varying

Hub mass, front $(\mathrm{kg})$

45

Vehicle body mass $(\mathrm{kg})$

Occupant and seat parameters

Occupant and seat mass (kg)

Occupant and seat bounce stiffness $(\mathrm{N} / \mathrm{m})$

$2.84 \mathrm{e} 4$

Seat damping $(\mathrm{Ns} / \mathrm{m})$ 
Table 3. Natural frequencies of the vehicle used in numerical simulations

System mode

\section{Vehicle modes}

Vehicle body heave mode

Vehicle body pitch mode

Vehicle body roll mode

Vehicle wheel hop or hub mode

Occupant and seat modes

Bounce mode

Pitch mode

Roll mode
$9 \mathrm{~Hz}$

System natural frequency

$1.75 \mathrm{~Hz}$

$2 \mathrm{~Hz}$

$2.5 \mathrm{~Hz}$

$13,14 \mathrm{~Hz}$

$6.5 \mathrm{~Hz}$

$4 \mathrm{~Hz}$ 
Table 4. Parameter values used in predicting occupant response.

\section{System parameter}

Parameter value

\section{Vehicle parameters}

Tyre stiffness $(\mathrm{N} / \mathrm{m})$

Suspension stiffness, front $(\mathrm{N} / \mathrm{m})$

28000

Suspension stiffness, rear $(\mathrm{N} / \mathrm{m})$

20000

Suspension damping, front $(\mathrm{N} / \mathrm{m})$

4000

Suspension damping, rear $(\mathrm{N} / \mathrm{m})$

2000

$\begin{array}{ll}\text { Suspension stiffness in series, front }(\mathrm{N} / \mathrm{m}) & 1 \mathrm{e} 5\end{array}$

$\begin{array}{ll}\text { Suspension stiffness in series, rear }(\mathrm{N} / \mathrm{m}) & 1 \mathrm{e} 5\end{array}$

Hub mass, front $(\mathrm{kg}) \quad 42$

Hub mass, rear $(\mathrm{kg}) \quad 35$

$\begin{array}{ll}\text { Roll bar stiffness }(\mathrm{Nm} / \mathrm{rad}) & 1 \mathrm{e} 5\end{array}$

Vehicle body mass (kg) 940

$\begin{array}{ll}\text { Vehicle pitch inertia }\left(\mathrm{kgm}^{2}\right) & 1000\end{array}$

$\begin{array}{ll}\text { Vehicle roll inertia }\left(\mathrm{kgm}^{2}\right) & 500\end{array}$

Distance from roll centre to left wheel (m) 1.1

Distance from roll centre to right wheel (m) 1.1

Distance from pitch centre to front wheel (m) $\quad 0.89$

$\begin{array}{ll}\text { Distance from pitch centre to rear wheel }(\mathrm{m}) & 1.57\end{array}$

\section{Occupant and seat parameters}

$\begin{array}{lr}\text { Occupant and seat mass (kg) } & 80\end{array}$

$\begin{array}{lr}\text { Occupant and seat pitch inertia }\left(\mathrm{kgm}^{2}\right) & 8\end{array}$

$\begin{array}{ll}\text { Occupant and seat roll inertia }\left(\mathrm{kgm}^{2}\right) & 10\end{array}$

$\begin{array}{lr}\text { Occupant and seat bounce stiffness }(\mathrm{N} / \mathrm{m}) & 5 \mathrm{e} 4\end{array}$

Occupant and seat bounce damping (Ns/m) 300

Occupant and seat roll stiffness (Nm/rad) $0.1 \mathrm{e} 3$

$\begin{array}{ll}\text { Occupant and seat roll damping (Nms/rad) } & 125\end{array}$

$\begin{array}{ll}\text { Occupant and seat pitch stiffness }(\mathrm{Nm} / \mathrm{rad}) & 5 \mathrm{e} 3\end{array}$

$\begin{array}{ll}\text { Occupant and seat pitch damping (Nms/rad) } & 150\end{array}$

Length to centre of the seat from CG along $X$ axis (m) 0.4

Length to centre of the seat from Roll centre along $Y$ axis (m) 0.6 
Table 5. Discomfort definition and scaling used by Ibicek and Thite (2012, 2014).

\begin{tabular}{lc}
\hline \multicolumn{1}{c}{ Perception } & Rating \\
\hline Not discomfortable & 1 \\
Noticeable but not discomfortable & 2 \\
Slightly discomfortable & 3 \\
Discomfortable & 4 \\
Highly discomfortable & 5 \\
\hline
\end{tabular}




\section{List of Figures}

Figure 1: Typical measured discomfort index curve for a given acceleration stimulus.

Figure 2: A 3 DOF model of vehicle suspension-occupant dynamics. a) an ordinary model and b) a model with compliant spring in series.

Figure 3: 10 DOF model of vehicle suspension-occupant dynamics.

Figure 4: Steven's power law exponent showing growth sensitivity. a) heave, b) pitch and c) roll inputs respectively.

Figure 5: Steven's power law constant and smooth variation approximation. bounce or heave input, $ー$ - - pitch input and $-\bullet-\bullet$ roll input

Figure 6: Comparison of responses on a) as measured on vehicle body and numerically simulated b) vehicle body and c) wheel. For numerical simulations based on an ordinary model, and a model based on compliance in series, - - - . The damping coefficient used is $2000 \mathrm{Ns} / \mathrm{m}$.

Figure 7: Variation of displacement response magnitude as a function of frequency and damping. a) an ordinary model and b) a model with damping and a spring in series.

Figure 8: Vertical input in phase. a) vehicle response and b) seat-occupant response. bounce, $-\longrightarrow$ pitch $(\mathrm{rad} / \mathrm{m}),-\cdot-\cdot-\operatorname{roll}(\mathrm{rad} / \mathrm{m})$.

Figure 9: Vertical input where front and rear wheels move out of phase. a) vehicle response and b) seat-occupant response. — bounce, $-\longrightarrow$ pitch $(\mathrm{rad} / \mathrm{m}),-\cdot-\cdot-\operatorname{roll}(\mathrm{rad} / \mathrm{m})$.

Figure 10: Vertical input where right and left wheels move out of phase. a) vehicle response and b) seat-occupant response. —— bounce, $-\ldots$ pitch $(\mathrm{rad} / \mathrm{m}),-\cdot-\cdot-\operatorname{roll}(\mathrm{rad} / \mathrm{m})$.

Figure 11: Calculated acceleration at seat-occupant for given input. —— heave input, - - pitch input, $-\cdot-\cdot-$ roll input.

Figure 12: Predicted DCI based on calculated acceleration at seat-occupant for given input. heave input, -- - pitch input and $-\cdot-\cdot-$ roll input.

Figure 13: The effect of occupant-seat parameter variation on the comfort performance for heave input $-75 \%$ increase in the damping coefficient and stiffness decreased to $20 \%$ relative to baseline values. 


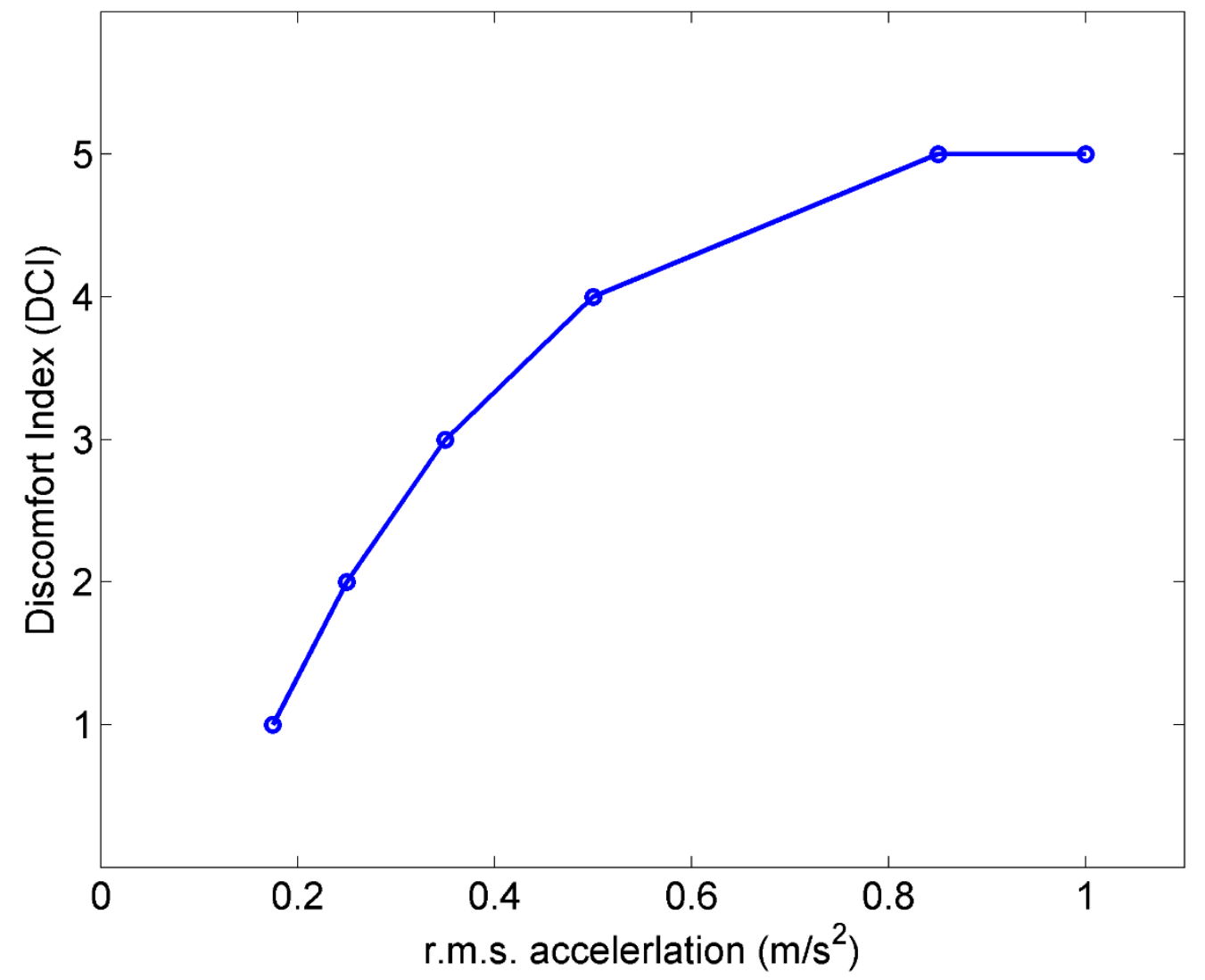

Figure 1: Typical measured discomfort index curve for a given acceleration stimulus. 

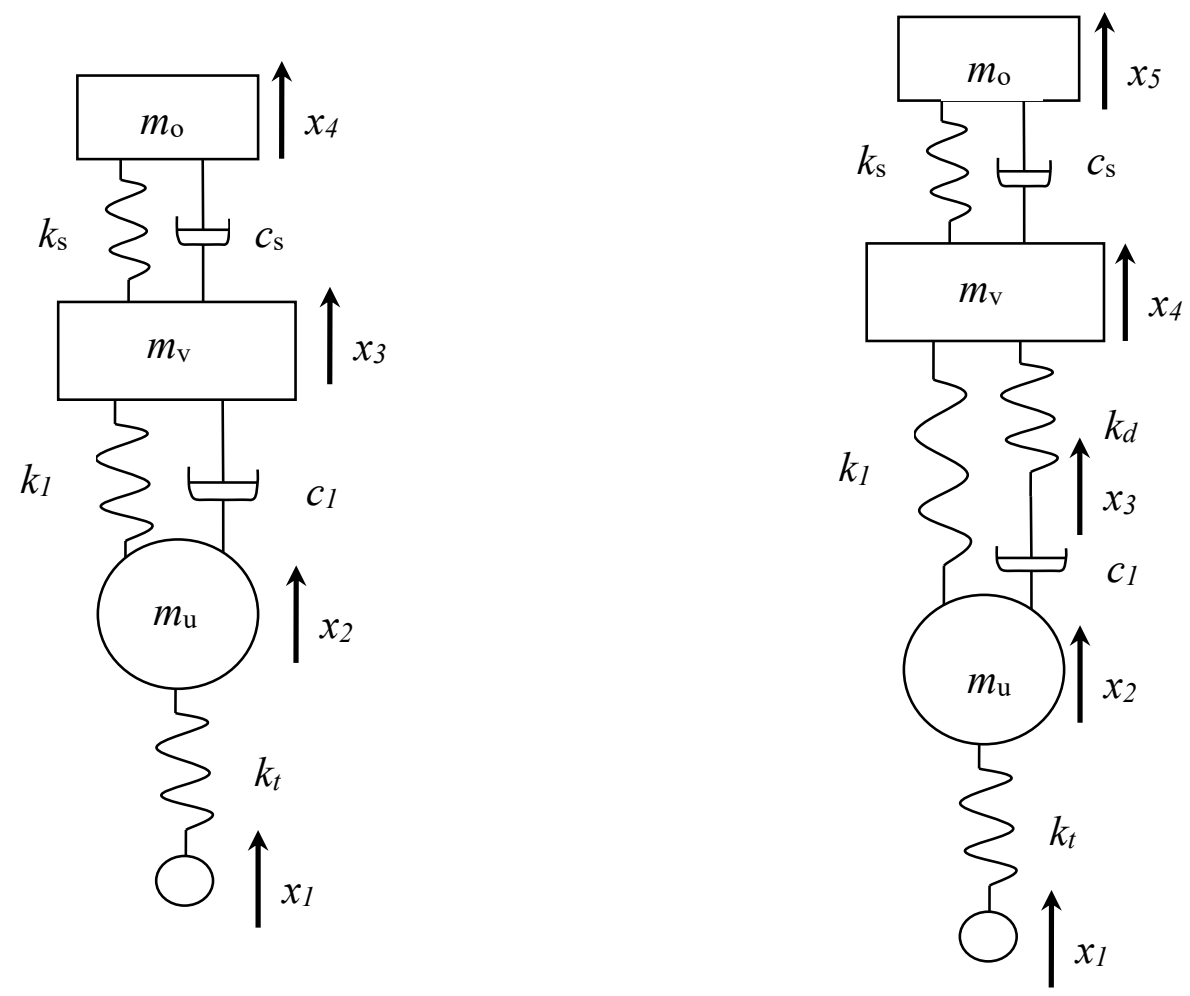

Figure 2: A 3 DOF model of vehicle suspension-occupant dynamics. a) an ordinary model and b) a model with compliant spring in series. 


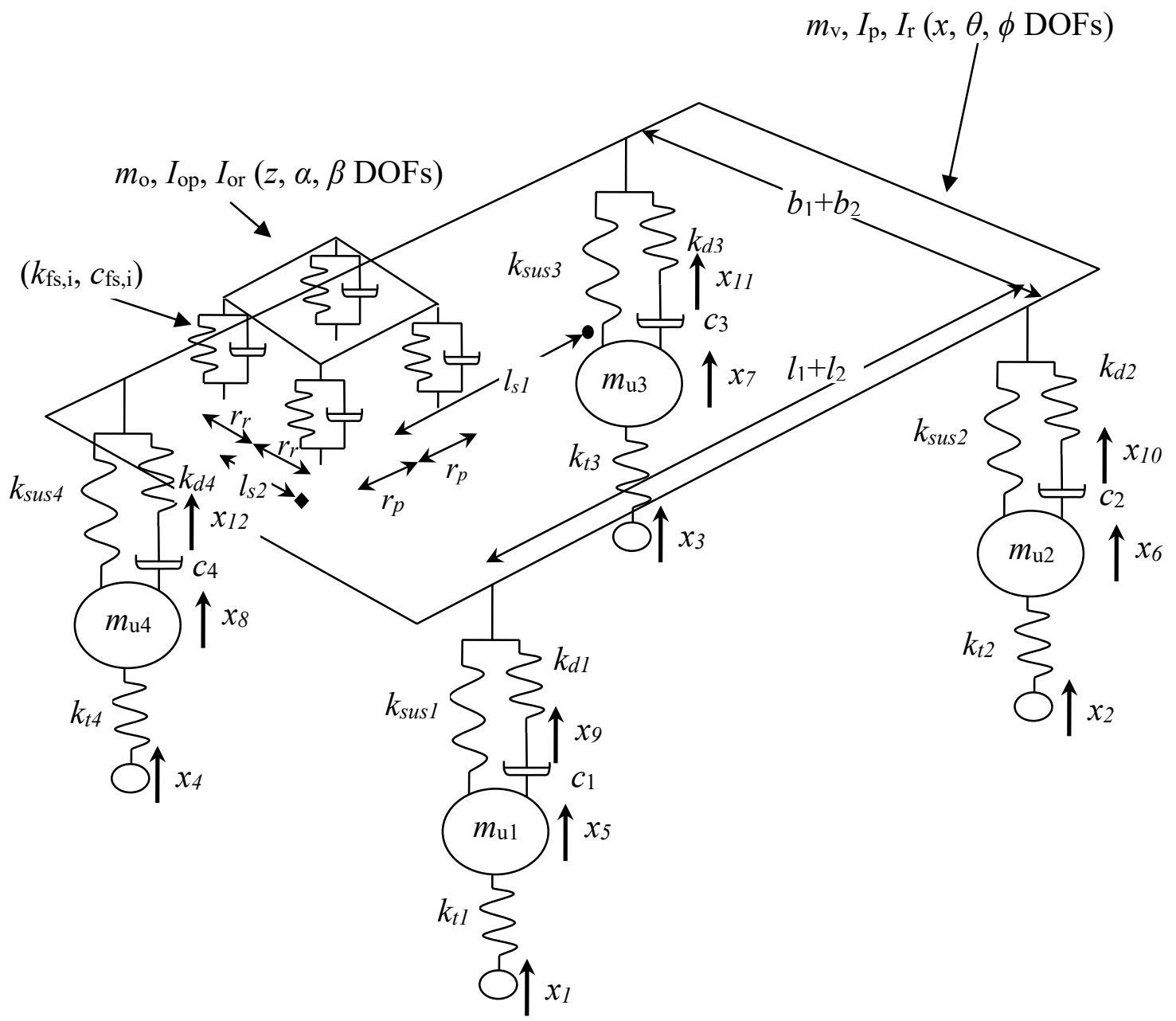

Figure 3: 10 DOF model of vehicle suspension-occupant dynamics. 
a)

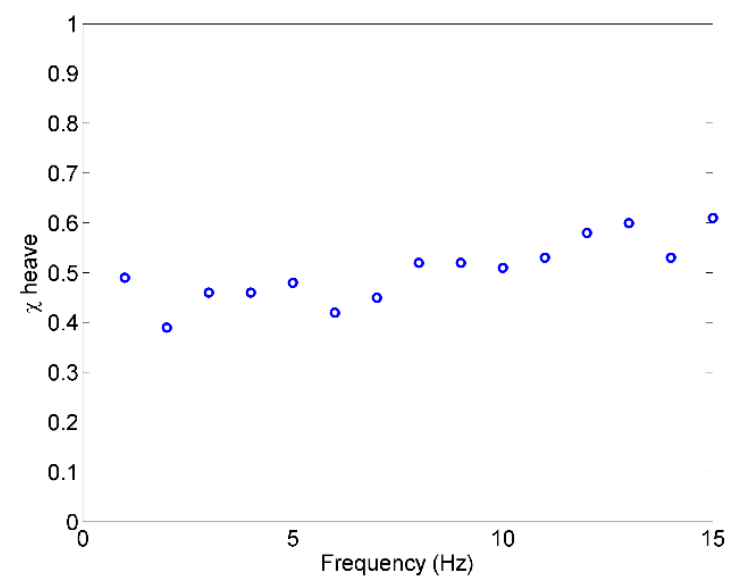

c) b)

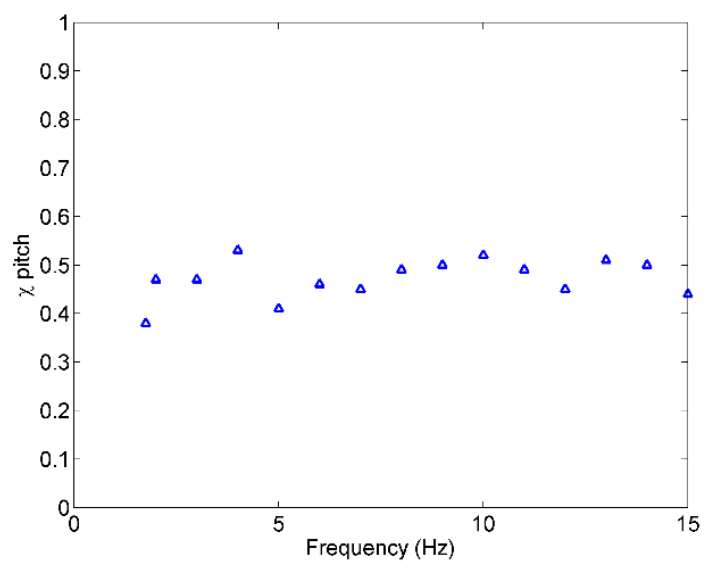

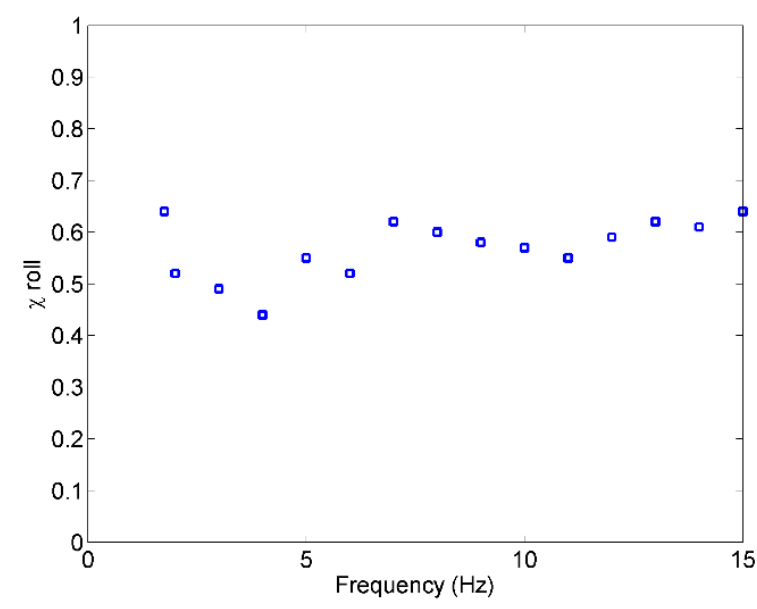

Figure 4: Steven's power law exponent showing growth sensitivity. a) heave, b) pitch and c) roll inputs respectively. 


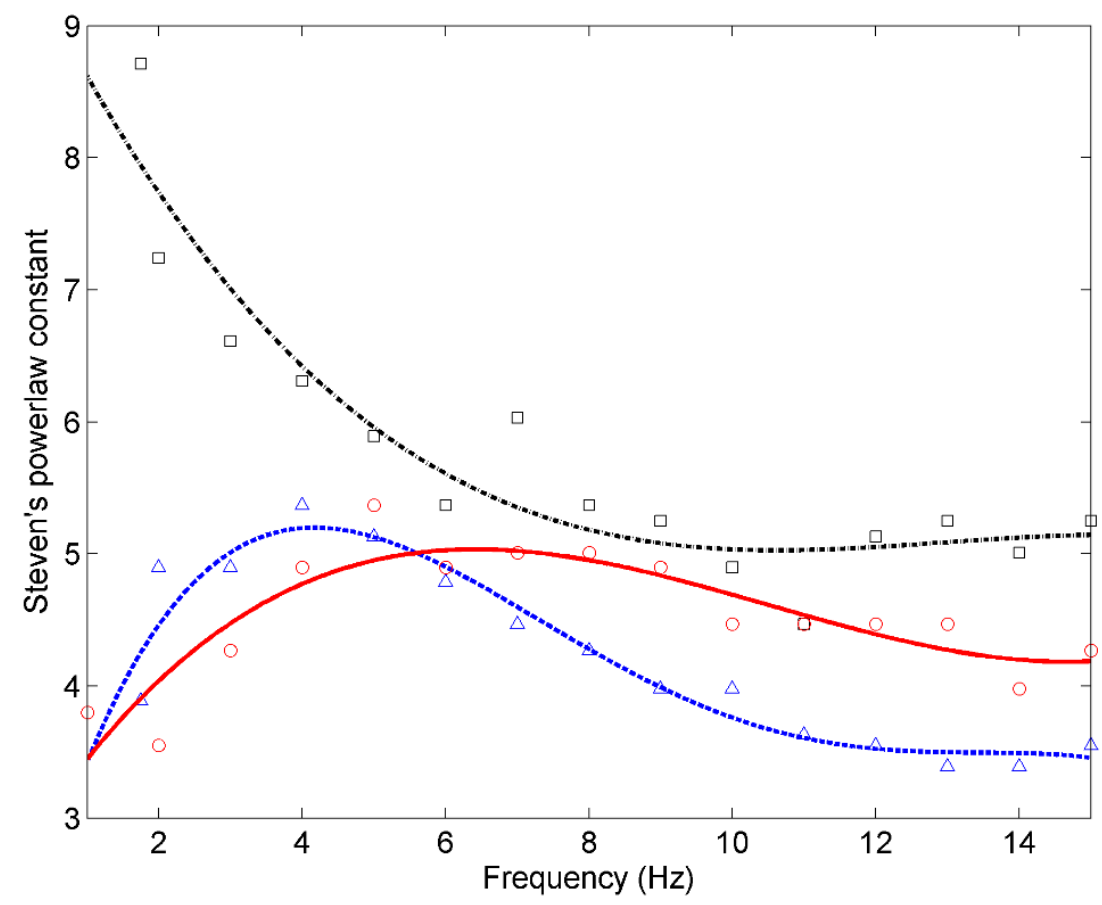

Figure 5: Steven's power law constant and smooth variation approximation.

bounce or heave input, - - - pitch input and $-\cdots \cdots$ roll input. 
a)

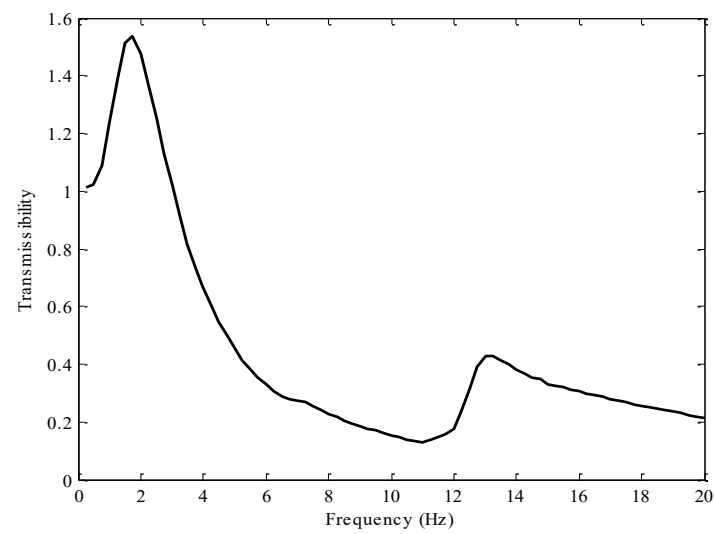

b)

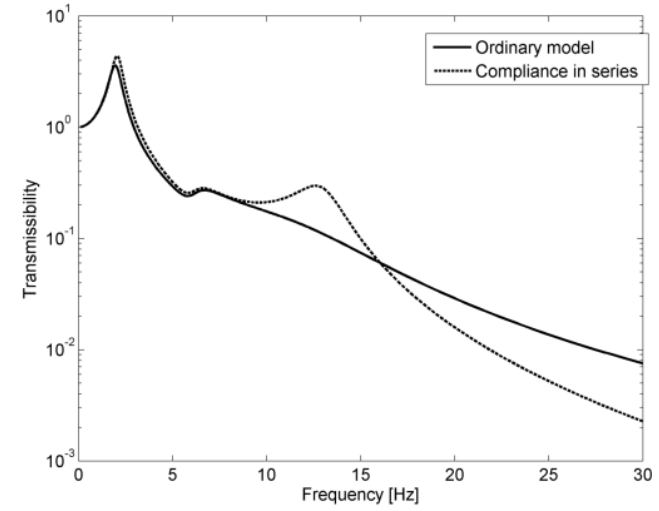

c)

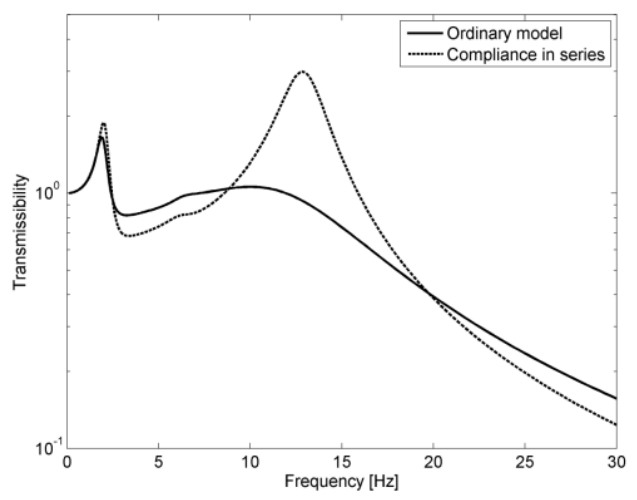

Figure 6: Comparison of responses on a) as measured on vehicle body and numerically simulated b) vehicle body and c) wheel. For numerical simulations based on an ordinary model, — and a model based on compliance in series, - - - -. The damping coefficient used is $2000 \mathrm{Ns} / \mathrm{m}$. 
a)

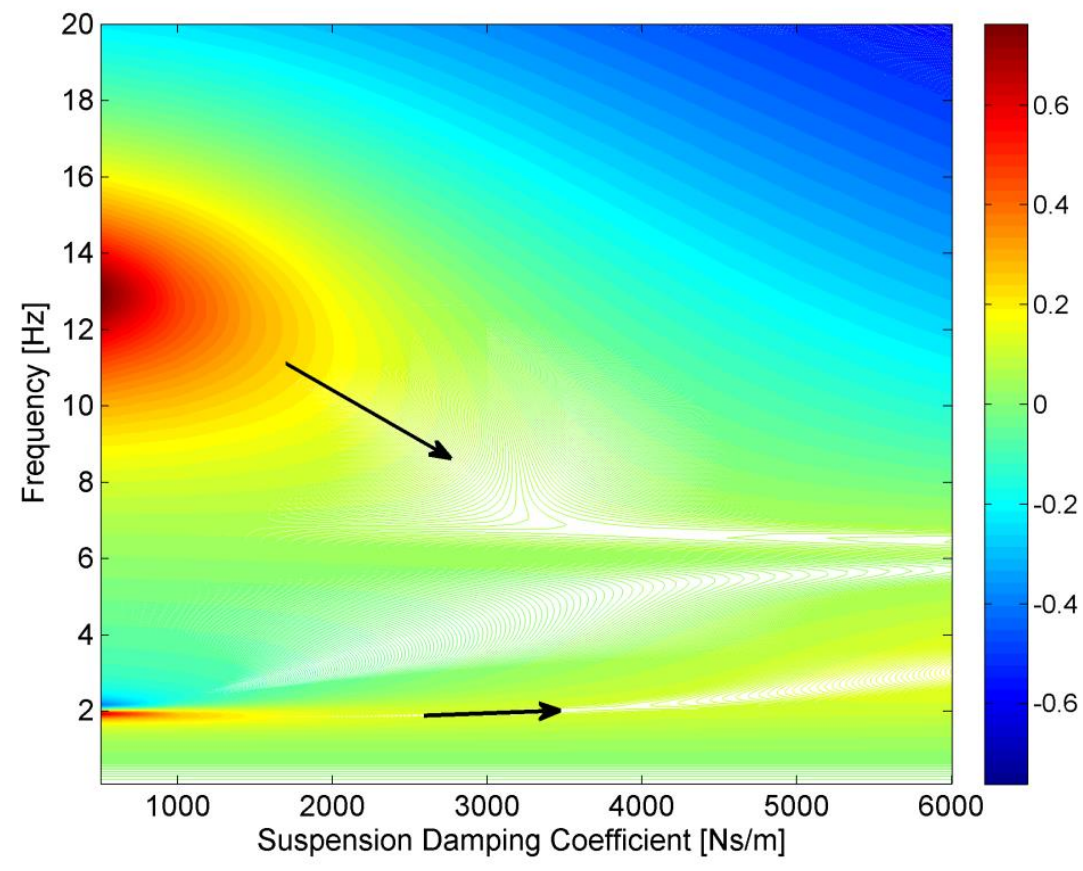

b)

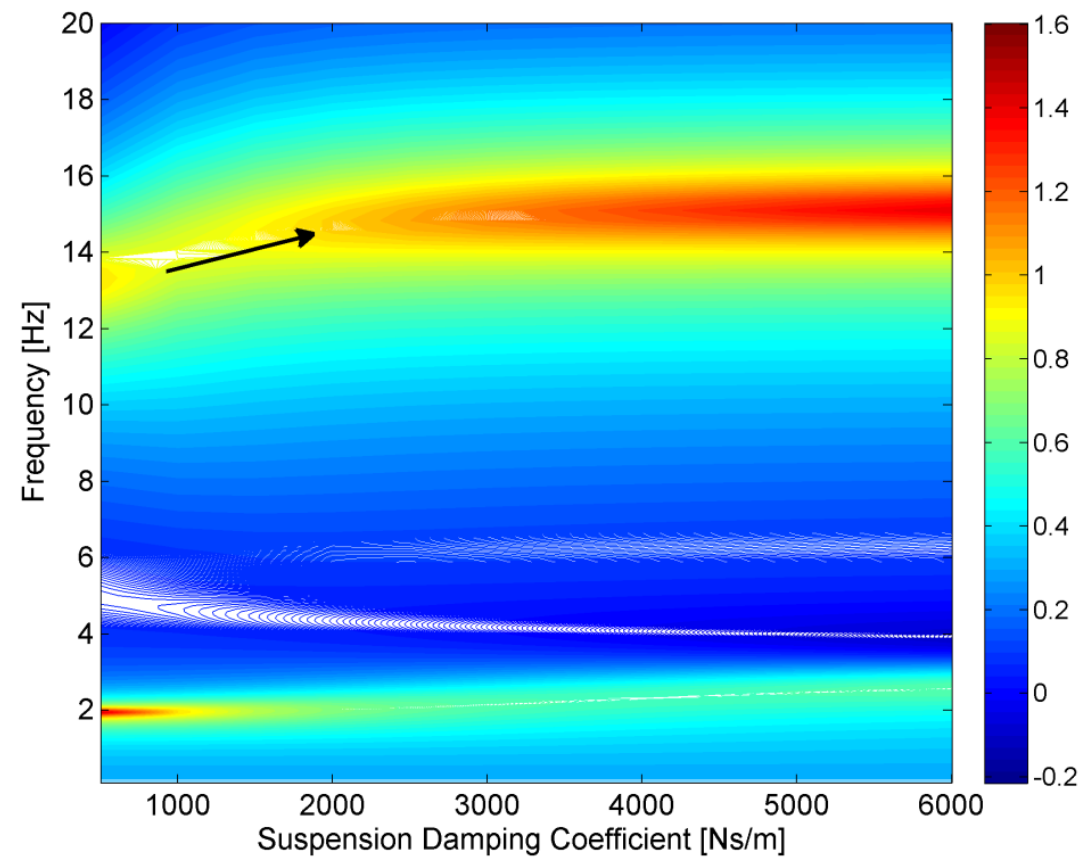

Figure 7: Variation of displacement response magnitude as a function of frequency and damping. a) an ordinary model and b) a model with damping and a spring in series. 
a)

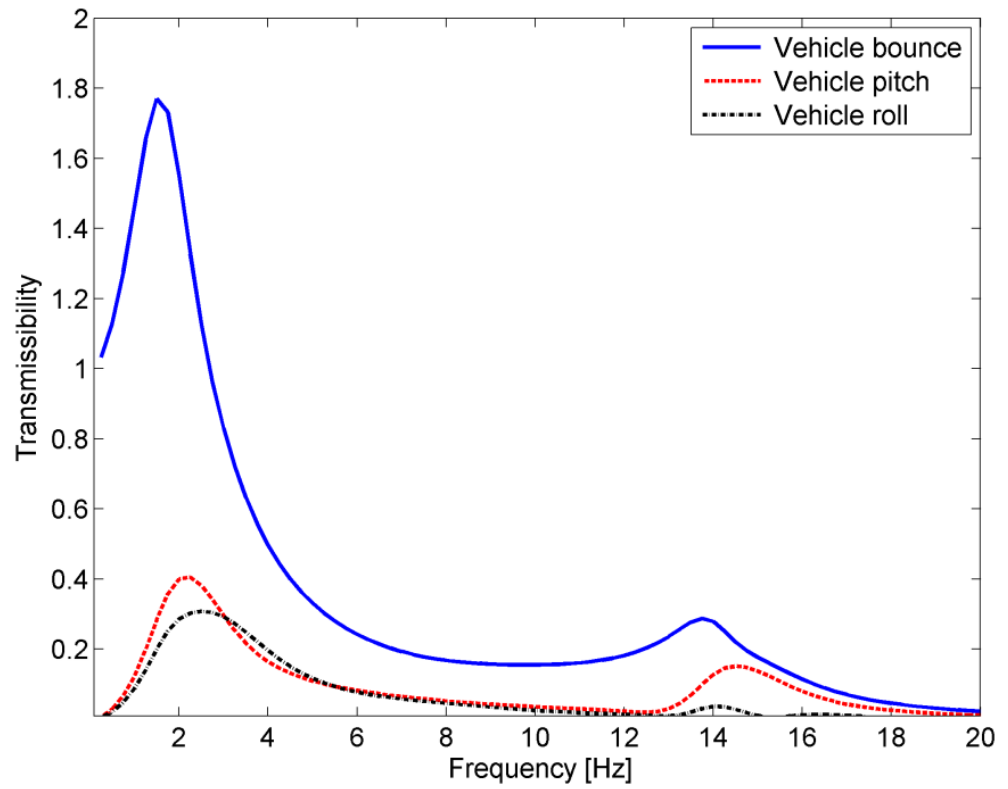

b)

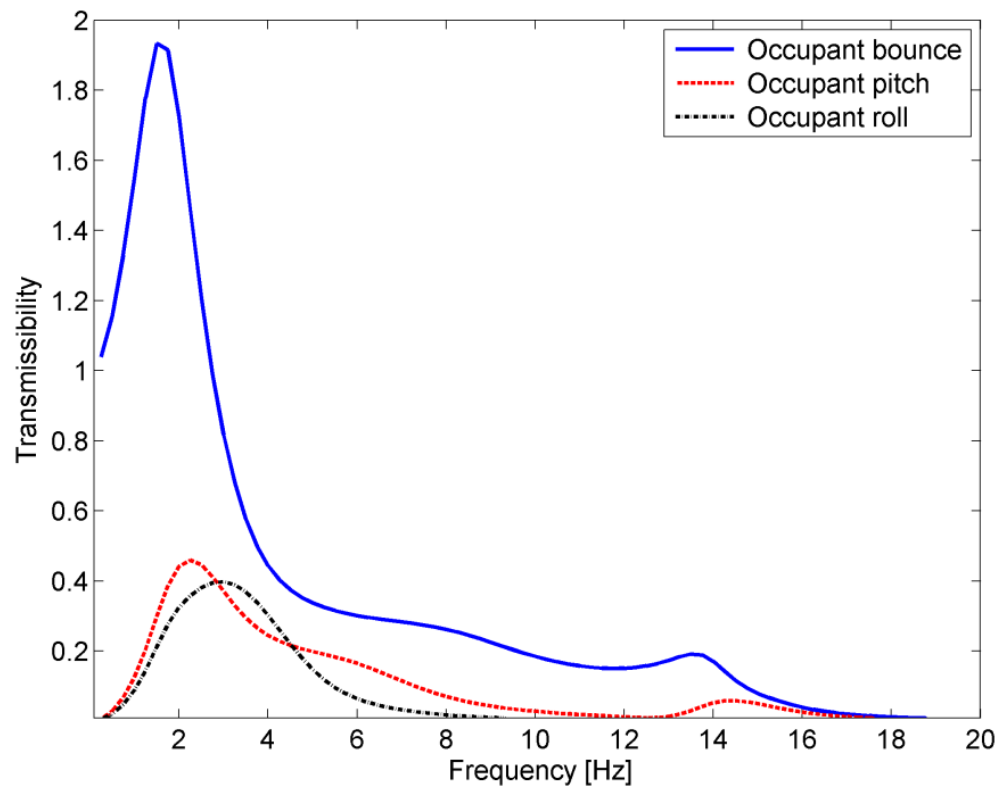

Figure 8: Vertical input in phase. a) vehicle response and b) seat-occupant response. bounce, - - - pitch $(\mathrm{rad} / \mathrm{m}),-\cdot-\cdot-\operatorname{roll}(\mathrm{rad} / \mathrm{m})$. 
a)

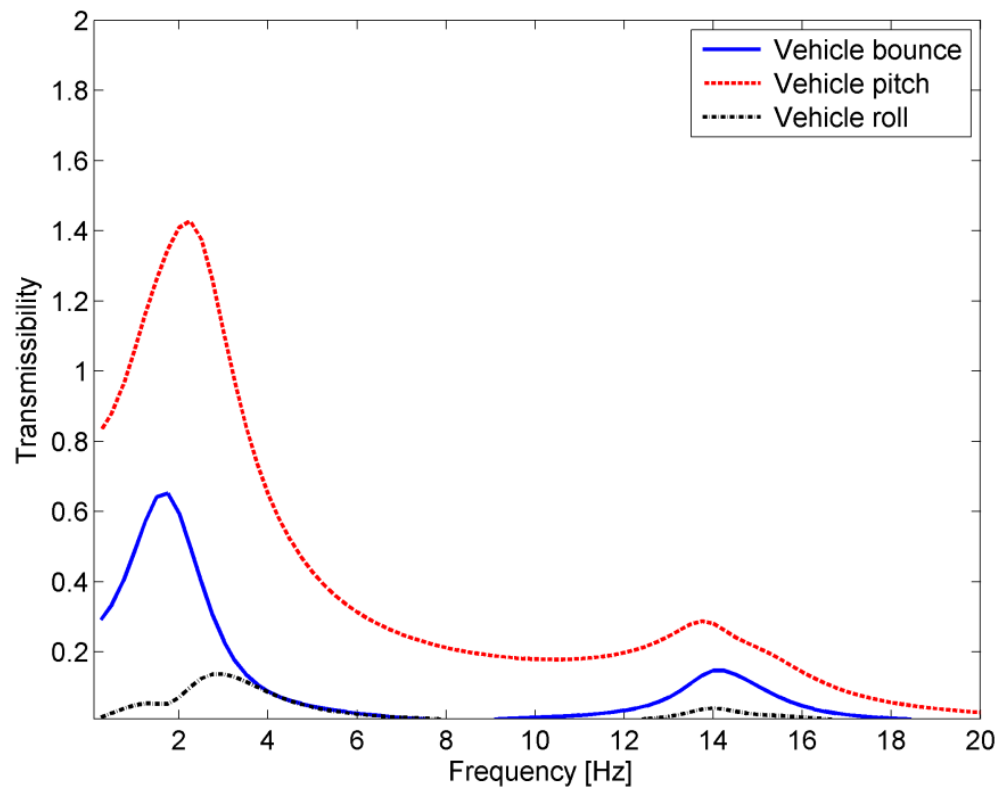

b)

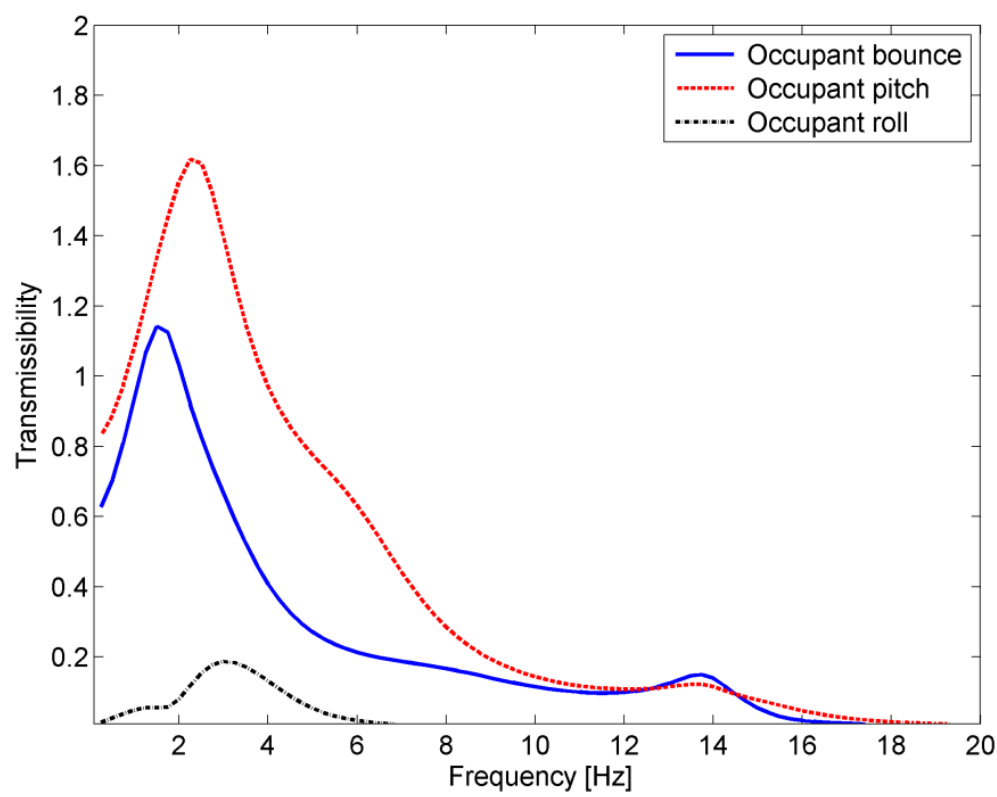

Figure 9: Vertical input where front and rear wheels move out of phase. a) vehicle response and b) seat-occupant response. bounce, -- pitch $(\mathrm{rad} / \mathrm{m}),-\cdot-\cdot-\operatorname{roll}$ $(\mathrm{rad} / \mathrm{m})$. 
a)

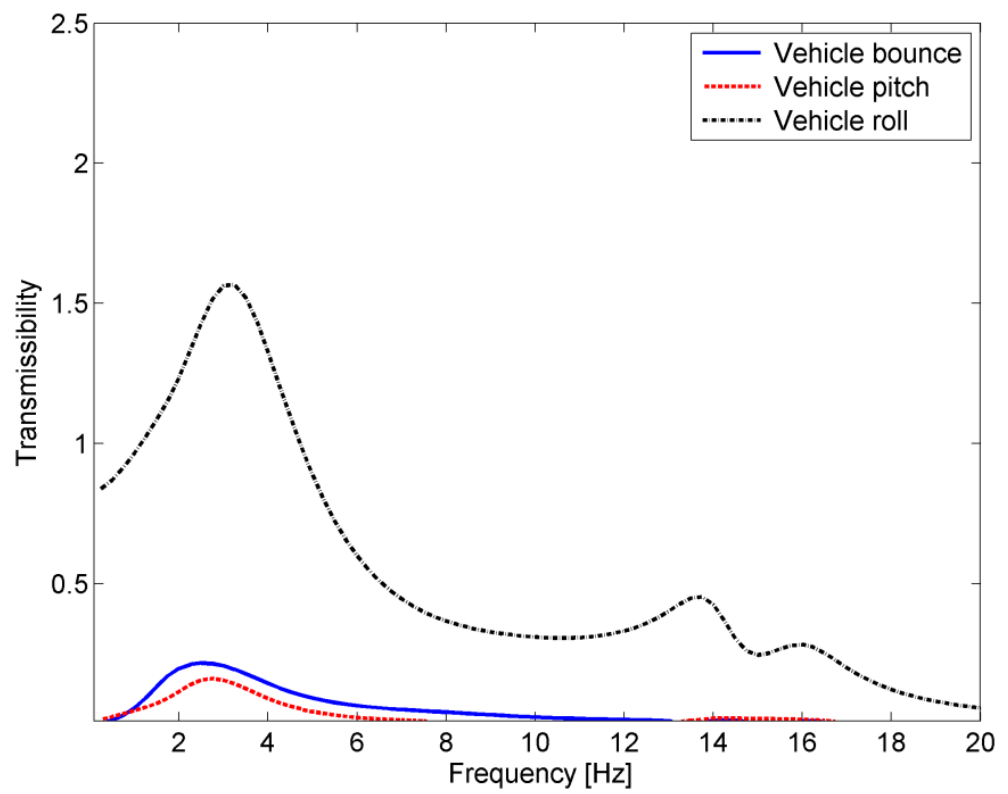

b)

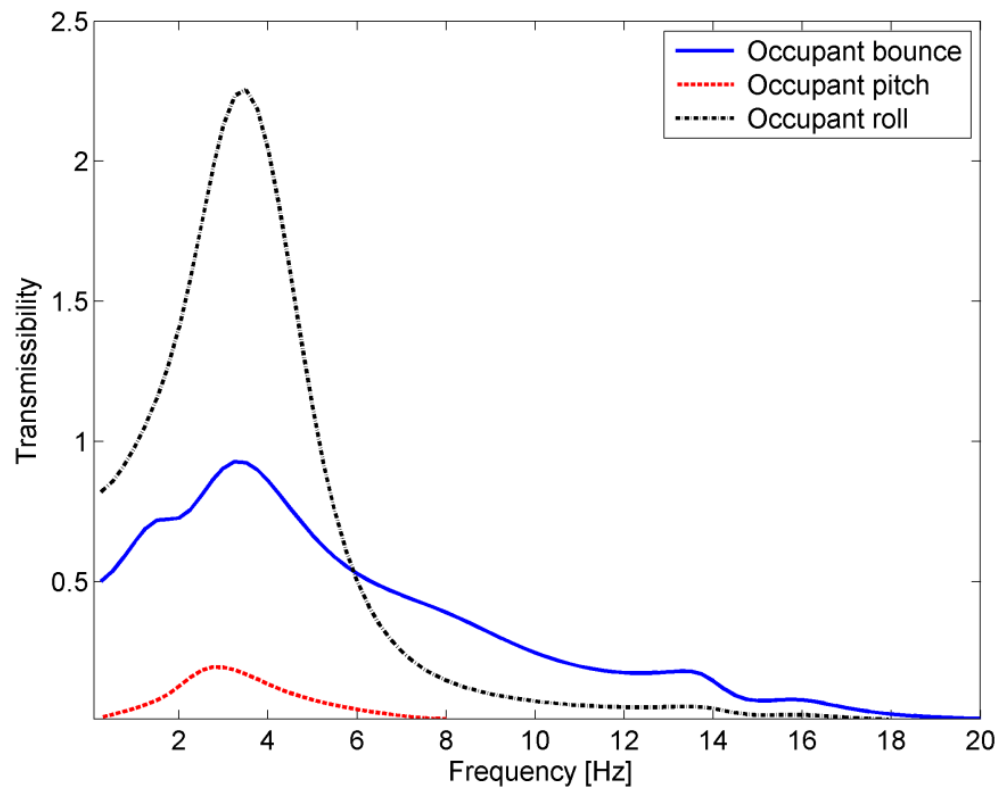

Figure 10: Vertical input where right and left wheels move out of phase. a) vehicle response and b) seat-occupant response. bounce, -- pitch $(\mathrm{rad} / \mathrm{m}),-\cdot-\cdot-$ roll $(\mathrm{rad} / \mathrm{m})$. 


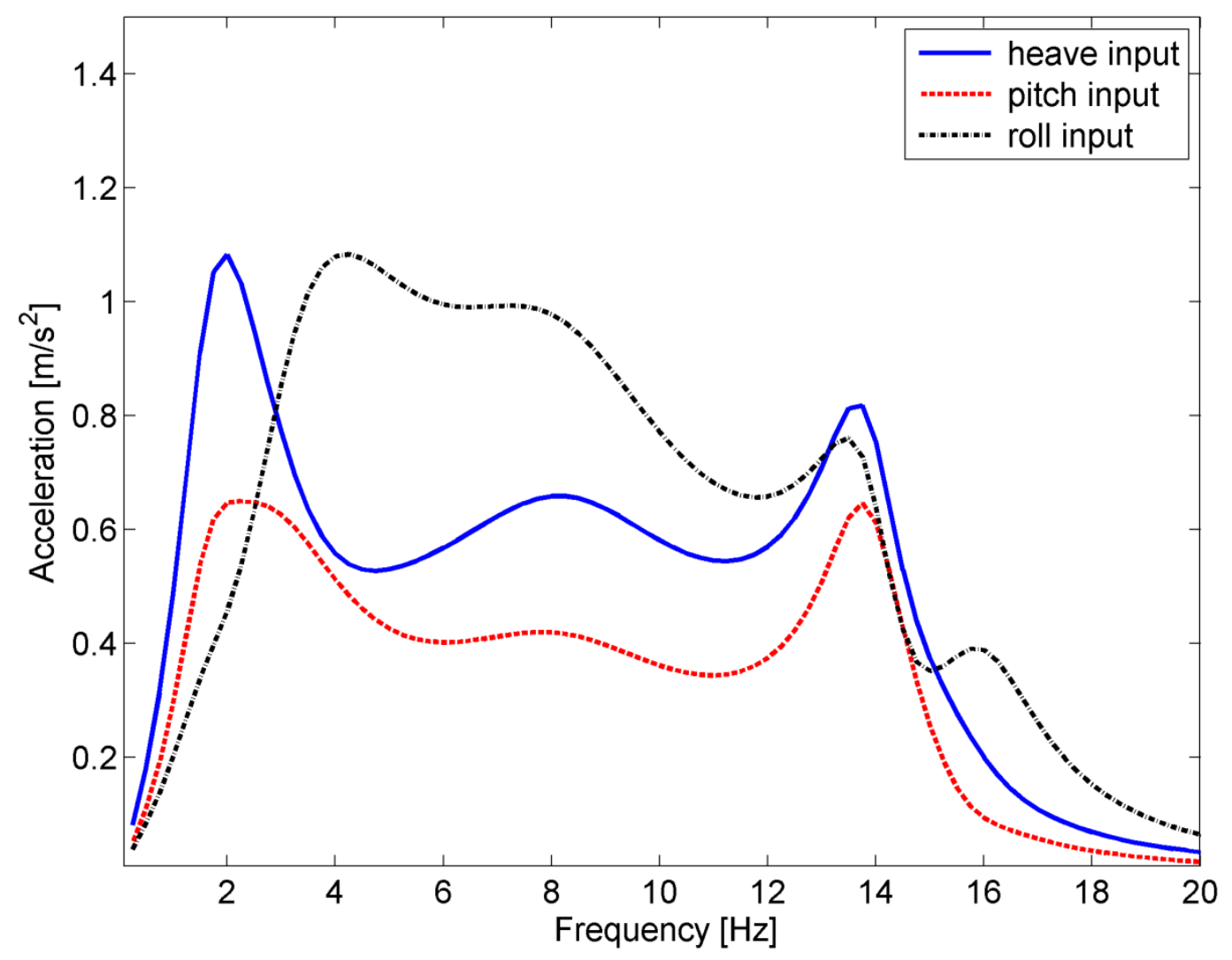

Figure 11: Calculated acceleration at seat-occupant for given input. — heave input, - - - pitch input, $-\cdots-\cdot-$ roll input. 


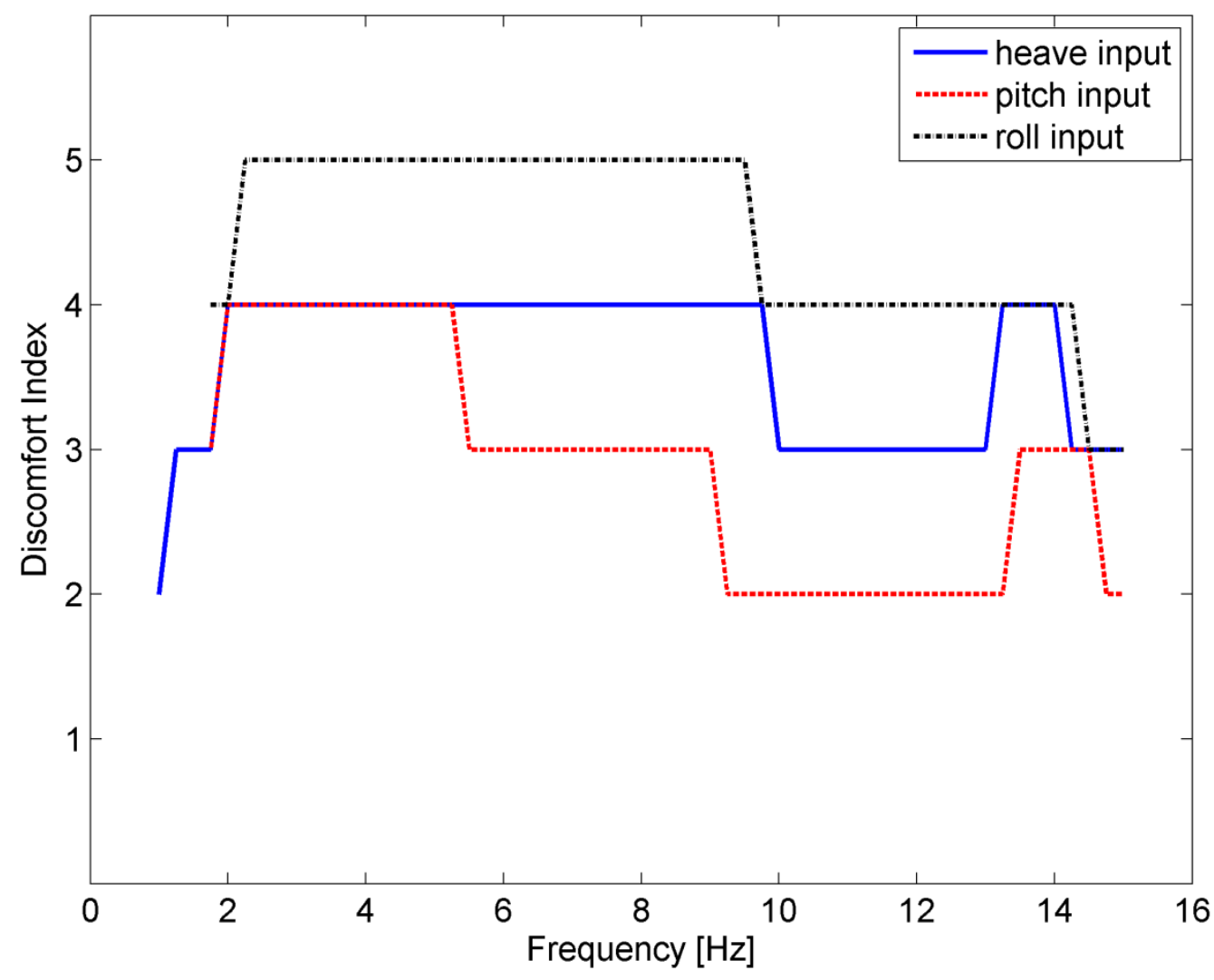

Figure 12: Predicted DCI based on calculated acceleration at seat-occupant for given input.

- heave input, -- pitch input and $-\cdot-\cdot-$ roll input. 


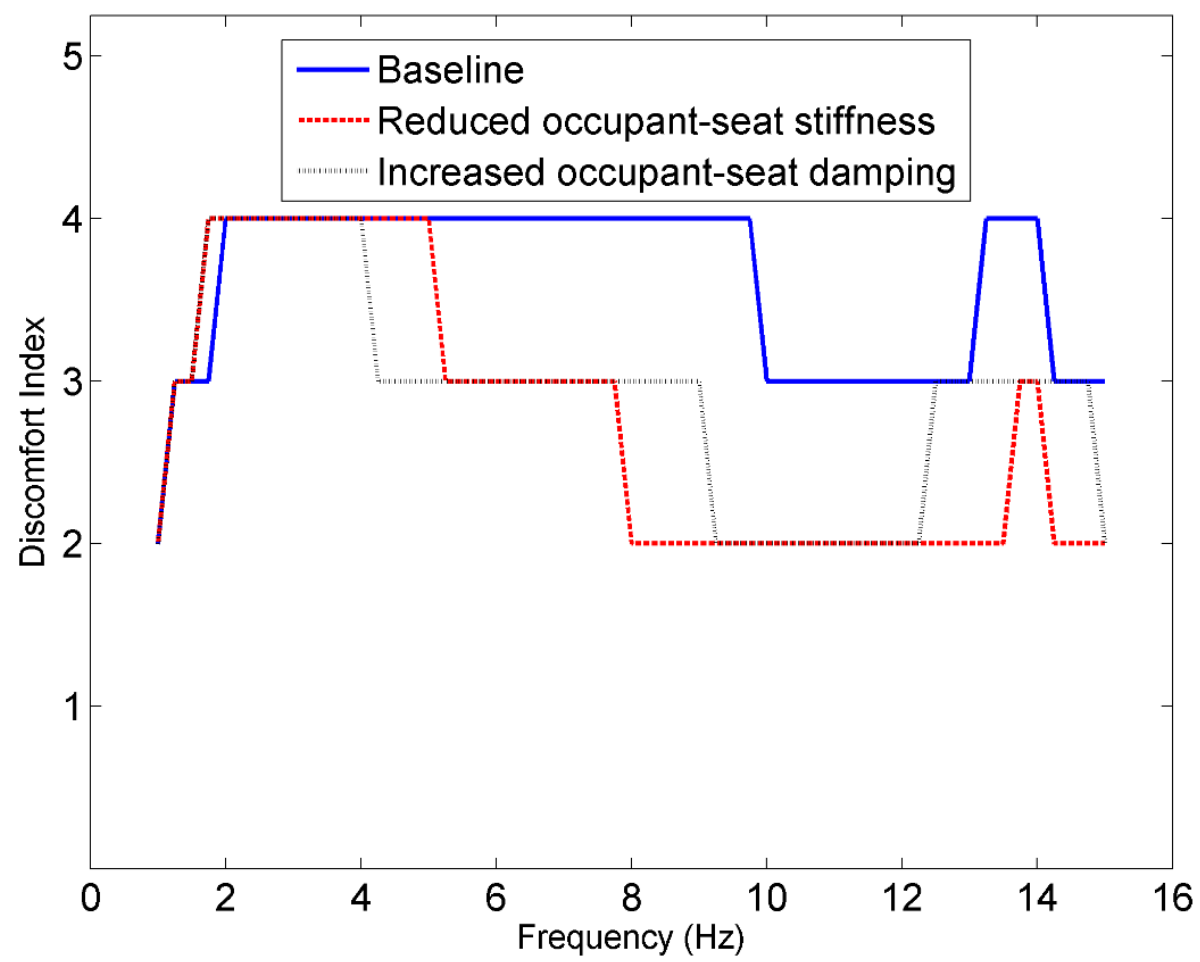

Figure 13: The effect of occupant-seat parameter variation on the comfort performance for heave input $-75 \%$ increase in the damping coefficient and stiffness decreased to $20 \%$ relative to baseline values. 